RUNNING HEAD: INTIMATE RELATIONS

An Integrative Contextual Behavioral Science Model of Intimate Relations

\author{
Jonathan W. Kanter ${ }^{\mathrm{a}}$ \\ Adam M. Kuczynski ${ }^{a}$ \\ Katherine E. Manbeck ${ }^{\mathrm{a}}$ \\ Mariah D. Corey ${ }^{\mathrm{a}}$ \\ Elliot C. Wallace ${ }^{\mathrm{a}}$ \\ ${ }^{\text {a}}$ University of Washington \\ Seattle, WA 98195 \\ United States of America
}

Correspondence: Jonathan W. Kanter, Box 351525, University of Washington, Seattle, WA 98195. Email: jonkan@uw.edu 


\begin{abstract}
Intimate relationships matter to health and happiness, and the field of relationship science is vast. However, the scope of the field and the abundance of precise micro-theories has presented obstacles to the development of integrative theories with contextual-behavioral science foundations that are oriented towards application of findings in domains of public health significance. Derived from the well-validated Interpersonal Process Model, which described intimacy as a dyadic exchange in which Person A engages in a vulnerable self-disclosure, Person B enacts a response, and Person A perceives the response as responsive, we present an integrative, analytic-abstractive, contextual-behavioral science model of intimate relations. The model describes the intimacy process as a set of functional relations between the behavior of Person A and a response of Person B, languaged as middle-level terms to facilitate crossdisciplinary applications. Three primary relations of the model are non-verbal emotional expression (Person A) and safety (Person B), verbal self-disclosure (Person A) and validation (Person B), and asking (Person A) and giving (Person B). The model also emphasizes the importance of self- and other-awareness and expressions of closeness as additional terms. Future research directions and potential applications are discussed.
\end{abstract}

Key words: Interpersonal relationships, intimacy, theory and research, contextual-behavioral science 
RUNNING HEAD: INTIMATE RELATIONS

\section{An Integrative Contextual Behavioral Science Model of Intimate Relations}

Relationships matter. This is clear for many of us from personal experience, and underscored by the ubiquity of relationships as a major theme across literature, the arts, and spiritual practices. The value of close relationships is substantiated by science as well. Overall, having poor social relationships is associated with the same level of mortality as smoking 15 cigarettes daily (Holt-Lunstad \& Smith, 2012) and double the influence of obesity (Holt-Lunstad, Smith, \& Layton, 2010). We are built by nature to require close, functional relationships across a range of interpersonal contexts and these relationships must thrive to maximize our well-being, health, and survival (Bugental, 2000; Cohen, 2004; House, Landis, \& Umberson, 1988; Ryff \& Singer, 2000). It is not surprising that relationships are often a major theme when individuals seek psychotherapy to alleviate distress and improve their lives, including but not limited to efforts within the contextual-behavioral tradition (e.g., Dahl, Stewart, Martell, \& Kaplan, 2014; Harris, 2009).

Contextual-behavioral science (CBS) could benefit from a unified model of relationships to guide research and practice, and a CBS model could benefit the larger field of psychological science as well. Prominent relationship scientists Duck and Perlman (1985) described their field as "a thousand islands" of separate research traditions and practices, while Reis (2007) noted that the field's scientific models and conclusions are "scattered and arcane," (p. 7) akin to the proverbial elephant and the hands of the blind men. Many scientists, including those within CBS (e.g., Maitland, Kanter, Manbeck, \& Kuczynski, 2017), appear to be studying isolated pieces of the relationship puzzle and few are working to synthesize the pieces into a unified whole. As per CBS (Hayes, Barnes-Holmes, \& Wilson, 2012; Zettle, Hayes, Barnes-Holmes, \& Biglan, 2016), the field may have produced a slew of isolated models that emphasize precision (With how much 
RUNNING HEAD: INTIMATE RELATIONS

detail is a particular phenomenon understood?) at the expense of scope (Can the models converge into a broader theory that accommodates multiple phenomena?) and depth (Are the models and theories consilient with other disciplines such as biology and evolution?).

From a CBS perspective, another issue is the application of scientific findings. Bradbury (2002) called for integrative theories and a greater applied orientation in research on relationships, with the stated goal of bringing about better relationships across domains in which relationships matter. Reis (2007) similarly suggested that, although research has documented that the success and failure of close relationships is a function of many personal characteristics and interpersonal processes, it is possible to identify central organizing principles that bring some order to the chaos. Reis specifically named perceived partner responsiveness (PPR) - the final outcome of a dyadic interpersonal process described by the Interpersonal Process Model (IPM; Reis \& Shaver, 1988) — as a promising candidate for a central organizing principle (Reis, 2007; Reis, Clark, \& Holmes, 2004; Reis \& Gable, 2015). In our view, principles such as PPR, especially if formulated in contextual-behavioral terms which emphasize functionally defined actions-in-context, may help integrate the often seemingly dissimilar manifestations of relationship processes in real-world interactions and relationships, and enable the development of more efficient and effective clinical interventions and other efforts to improve relationships.

In this paper, we employ CBS as a theoretical framework and present an integrative model of close, personal relationships. The model development process behind this paper has a long history. Sparked by the 2009 publication of A Guide to Functional Analytic Psychotherapy (Tsai et al., 2009), the first author began an exploration of the scientific and functionalcontextual bases of the terms awareness, courage, and love (ACL) as used in that book. Several trends were observed over time. First, the major themes of what came to be known as the ACL 
RUNNING HEAD: INTIMATE RELATIONS

model (e.g., Kohlenberg et al., 2015) converged significantly with the IPM, which has evolved into a prominent model within relationship science and generated a large volume of research findings with clinical relevance. Second, although the terms ACL were originally used to describe qualities of therapist behavior in Functional Analytic Psychotherapy (FAP; e.g., Tsai, Callaghan, \& Kohlenberg, 2013), we found that the terms also were applied as common clinical targets in FAP; in other words, the ideas were useful in conceptualizing and intervening on client behavior (Maitland et al., 2017).

These trends generated optimism that a full CBS model of intimate relations, appropriately incorporating the themes represented by ACL, was possible. The terms themselves, however, in our and others' opinions (cf., Darrow \& Follete, 2014; Kanter, Holman, \& Wilson, 2014), suffered from inadequate precision, lacked clear linkages to functional-contextual processes, and were not sufficiently integrated with the larger body of research findings generated by the IPM and relationship science to function as the bases of a CBS model without considerable reticulated developmental work. This work has subsequently occurred over several years. It consisted of functional analyses of the primary relational processes to which ACL, and the IPM, refer, to improve the precision of the model. The work also included extensive review and integration into the model of the volume of relationship research from other traditions, including social psychology, neuroscience, and developmental psychology, to improve its scope and depth. The work also involved demonstration of the evolving model's utility in generating laboratory-based component process research (Haworth et al., 2015; Manbeck, Kanter, Kuczynski, Maitland, \& Corey, in press); development of relevant measurement tools for process and outcome research related to the model (Kuczynski et al., in press); and completion of several pilot studies suggesting that the model was useful for framing successful mindfulness 
RUNNING HEAD: INTIMATE RELATIONS

(Kohlenberg et al., 2015), brief psychotherapeutic (Kanter, Kuczynski, Tsai, \& Kohlenberg, 2018), burn-out (Reyes Ortega, Kuczynski, Kanter, de Montis, \& Santos, 2019), FAP therapist training (Kanter, Tsai, Holman, \& Koerner, 2013) and other interventions (Manbeck et al., 2018).

The model of intimate relations presented in this paper is based on the above work. We start with seminal work from relationship science on PPR and the IPM. We reformulate and elaborate the dyadic interactions of the IPM in CBS terms as a series of reinforcing, functional relations, the components of which are summarized as middle-level terms, articulated to represent modifiable intervention targets. We review multiple research paradigms and findings and describe points of convergence that support each of these terms and our definitions of them. Our review is not exhaustive nor are the terms we propose meant to encapsulate a complete set of necessary and sufficient constructs for relational well-being. However, the model integrates some of the major findings across relationship science and identifies what we consider to be the primary, highly probable functional relations that occur in intimacy and, if targeted by interventions, may result in significant outcome improvements. We end with a brief review of relevant research directions and applications.

\section{Perceived Partner Responsiveness and the Interpersonal Process Model}

Figure 1 presents a summary of the original IPM as per Reis and Shaver (1988). The model centers on repeated day-to-day social interactions between partners in a relationship and how one interprets one's partner's behavior in those interactions. In this formulation, both partners enter a social interaction with particular motives, needs, goals, and fears, of which they may or may not be aware, and perceptual filters that influence how they will perceive their own and their partner's behavior. With these intrapersonal processes as context, the interpersonal 
RUNNING HEAD: INTIMATE RELATIONS

interaction unfolds in which Person A, the speaker, engages in a vulnerable disclosure of some nature at Turn 1, and Person B, the listener, enacts a response to the disclosure at Turn 2. The speaker then perceives the listener's response as expressing understanding, validation, and caring. This perception that the listener is responding to one's disclosure with understanding, validation, and caring is what is meant by PPR (Reis et al., 2004; Reis \& Gable, 2015). According to the IPM, the extent to which both partners reciprocally engage in such disclosures, enact responses to each other's disclosures, and perceive each other's responses as demonstrating responsiveness, predicts the degree of intimacy of the interaction and is foundational to the development of close, trusting, and personally satisfying relationships over time.

There is ample scientific support for the importance of all three primary elements of the IPM (vulnerable self-disclosure, enacted responsiveness, and perceived responsiveness). The model's seminal test involved a 45-minute “closeness-generating" procedure (i.e., the "fast friends" procedure) in which undergraduates reciprocally responded to 36 questions that were designed to prompt increasingly vulnerable responses on a turn-by-turn basis (Aron, Melinat, Aron, Vallone, \& Bator, 1997). Using this procedure, researchers have experimentally increased relational closeness compared to various control procedures including small-talk disclosures that lack vulnerability (Aron et al., 1997), vulnerable disclosures by one partner that lack reciprocity from the other (Sprecher, Treger, Wondra, Hilaire, \& Wallpe, 2013), and vulnerable disclosure by one individual without enacted responsiveness of any form from the other (Haworth et al., 2015).

In research on the IPM, PPR reliably emerges as the strongest predictor of relational outcomes across a variety of relationship types (Canevello \& Crocker, 2010; Gable, Gonzaga, \& Strachman, 2006; Laurenceau, Barrett, \& Pietromonaco, 1998; Manne et al., 2004; Reis, 
RUNNING HEAD: INTIMATE RELATIONS

Sheldon, Gable, Roscoe, \& Ryan, 2000). That said, enacted responsiveness at Turn 2 of the hereand-now interaction is also important (Haworth et al., 2015). The listener's high quality enacted responsiveness to self-disclosure strongly predicts PPR (Canevello \& Crocker, 2010; Collins \& Feeney, 2000; Debrot, Cook, Perrez, \& Horn, 2012; Gable et al., 2006; Maisel, Gable, \& Strachman, 2008), is a stronger predictor of PPR than are trait-level variables (Lakey, McCabe, Fisicaro, \& Drew, 1996; Vinokur, Schul, \& Caplan, 1987), and is associated with overall relational well-being (Feeney \& Collins, 2001, 2003; Gable et al., 2006).

\section{A Contextual-Behavioral Science Reformulation of the IPM}

The IPM offers a crucial foundation for a CBS model of intimate relationships. First, in light of substantial concerns about the replicability of psychological science (Open Science Foundation, 2015), as discussed briefly above the major tenants of the IPM appear to be robust across a range of research paradigms and samples. Second, the constructs enumerated in the IPM - specifically vulnerable self-disclosure and enacted responsiveness - can be conceptualized as mutable behavioral processes and are thus suitable for contextual-behavioral interventions aimed at improving relationships. As per CBS (Hayes et al., 2012), the identification of here-and-now, behavioral characteristics of social interactions (i.e., actions-in-context) is beneficial because interventionists may more easily operationalize, identify, and teach these variables as operant skills compared to other constructs that are less easily referenced to here-and-now behavior (e.g., genetics, attachment styles).

We redefine and elaborate the IPM's primary constructs of vulnerability, enacted responsiveness, and perceived responsiveness as a set of highly probable operant or functional relations in the development of close, trusting relationships. At the simplest level, the IPM presents a hypothesis of a functional relation: Given an interpersonal interaction in which both 


\section{RUNNING HEAD: INTIMATE RELATIONS}

partners desire closeness (antecedent), vulnerable self-disclosure (behavior), when followed by responsiveness (consequence), is more likely to occur in the future, resulting in reciprocal affiliative behavior and, ultimately, closeness and connection. In an early exploration of this model, we directly tested and supported the hypothesis that enacted responsiveness is reinforcing, showing that vulnerable disclosures by a speaker only increased in depth when followed by this consequence (Haworth et al., 2015). This formulation is consistent with Cordova and Scott's (2001) behavior-analytic conceptualization of intimacy as a behavioral process in which the speaker engages in vulnerable behavior (i.e., vulnerable to interpersonal punishment) and the listener's response is naturally reinforcing rather than punishing, increasing the frequency of the speaker's vulnerable behavior.

Consistent with the CBS notion of analytic-abstractive theoretical models (Hayes et al., 2012; Kanter et al., 2014), our approach emphasizes the foundational behavioral principle of a functional relation but departs from the behavior-analytic emphasis on idiographic assessment as the primary means of determining targets (e.g., Baer, Wolf, \& Risley, 1968), and departs from behavioral language to describe the model (with a few exceptions, discussed below). Instead, in CBS, constructs of 3analytic-abstractive models may be defined as behavioral, action-oriented, "middle-level" terms: higher-level summaries of important converging research findings, languaged to be user-friendly and to facilitate mainstream scientific investigation and real-world applications of the model (Vilardaga, Hayes, Levin, \& Muto, 2009). We define what may be considered middle-level terms with functional relations as their basis.

Figure 2 presents our model. The basic dyadic interactional sequence of the IPM that produces PPR is described as a functional relation in which the speaker engages in a behavior ("vulnerability") at Turn 1 and the listener provides a response ("enacted response") which 


\section{RUNNING HEAD: INTIMATE RELATIONS}

functions as a reinforcing consequence at Turn 2. This response forms the antecedent of a subsequent functional relation in which the speaker, at Turn 3, engages in their own response (“expression of closeness") to the listener's responsiveness, functioning both as a reinforcing consequence to the listener and a subsequent vulnerable self-disclosure. In this way, the interaction may continue and evolve in a recursive fashion.

Evidence at several levels of analysis exists to support the claim that these are indeed reinforcing functional relations. At the neurobiological level, dopaminergic reward circuitry activates in response to sharing vulnerable emotions with trusted others (e.g., Rademacher, Schulte-Rüther, Hanewald, \& Lammertz, 2015; Wagner et al., 2015) which, according to Morelli, Torre, and Eisenberger (2014) may specifically be a function of perceiving the listener's enacted response as responsive (i.e., PPR). At the behavioral level, an experimental variant of the fast friends procedure provides support for the reinforcing role of enacted responsiveness (Haworth et al., 2015). More specifically, the depth of the speaker's self-disclosure increased over the course of the fast friends procedure, but only when it was followed by responsive feedback from the listener, suggesting a reinforcing process. Likewise, Forest and Wood (2011) provided support that responsiveness is reinforcing at least for individuals with low self-esteem; specifically, they found that highly responsive feedback to emotional disclosure in this population resulted in more emotion words and more willingness to disclose in the future.

Our review and integration of the literature suggests the distinction of three highly probable, naturally occurring sub-relations within the primary vulnerability-responsiveness relation: (a) non-verbal emotional expression (or "showing yourself") with safety, (b) verbal selfdisclosure (or “expressing yourself”) with validation, and (c) asking with giving. In functional analysis, antecedents are traditionally defined in terms of environmental stimuli that set the 
RUNNING HEAD: INTIMATE RELATIONS

occasion for the relevant behaviors. Our model instead emphasizes the speaker's and listener's awareness of these antecedent conditions, including in the external environment and in themselves and each other (private behaviors). This creates additional "awareness" targets that are included in the model and conform to extant definitions of mindful awareness within CBS (CITE). The central organizing principle of relationship science, PPR, shows up in our model within the construct of awareness, specifically the speaker's awareness in the moment after the listener has enacted a response. See Table 1 for a definition of each term in the model.

\section{Non-verbal vulnerable emotional expression ("showing yourself") and safety}

Non-verbal emotional expression. The IPM defined the speaker's vulnerable behavior as any verbalization, expression, or action that reveals core aspects of the self to another person. Although non-verbal and verbal behavior occur in synchrony more frequently than they do not, research indicates that they are controlled by separate psychosocial and neurobiological systems and, as such, exist in separate functional relations (CITE). Thus, the first sub-relation in our model describes non-verbal vulnerable emotional expression as a distinct category, separate but related to verbal self-disclosure.

The importance of emotional expression in our social interactions is unequivocal. Since Darwin's (2005) proposal in 1872 that emotions are evolved adaptations that serve fundamental social communication functions, research has revealed that regulated, authentic expression of emotion is beneficial for social interaction in general (e.g., Parkinson, 1996; Van Kleef, 2010) and for the development of intimacy in particular (Kennedy-Moore \& Watson, 2001). In support of this idea, neurobiological models (Dimberg, Thunberg, \& Elmehed, 2000; Hasson, Ghazanfar, Galantucci, Garrod, \& Keysers, 2012; Jiang, Dai, Peng, Liu, \& Lu, 2012; Niedenthal, 2007; 
RUNNING HEAD: INTIMATE RELATIONS

Porges, 2011) suggest that we are hard-wired to display synchronized emotions during social interactions.

The flipside of emotional expression - emotional avoidance/suppression (Gross \& John, 2003; Hayes, Wilson, Gifford, Follette, \& Strosahl, 1996) - is problematic for relational wellbeing. It is well-established within CBS that experiential avoidance (i.e., avoidance of aversive private experiences) is associated with a host of problematic health (e.g., Hayes, Strosahl, et al., 2004) and interpersonal (Gerhart, Baker, Hoerger, \& Ronan, 2014) problems. Attempts to suppress emotional expression produce a host of interpersonal problems (Gross \& John, 2003; Srivastava, Tamir, McGonigal, John, \& Gross, 2009), including that the partner experiences the suppressor as unsafe and the interaction as stressful due to the disruption of the subtle nuances of natural facial expression that the partner expects (Butler et al., 2003).

Safety. We suggest the term "safety" to characterize the primary functional response to non-verbal vulnerable emotional expression. While the IPM defines responsiveness as the provision of understanding, validation, and care, we suggest these repertoires build from a foundation of safety, which is expressed both non-verbally and verbally. While the speaker is hard-wired to display emotional expressiveness in social interactions, the listener is hard-wired to mimic and reciprocate with exquisite sensitivity. This process provides safety and support for the speaker, shaping the overall quality and trajectory of the interaction (Dimberg et al., 2000; Hasson et al., 2012; Jiang et al., 2012; Niedenthal, 2007; Porges, 2011).

For the listener, following the maxim "first do no harm," we start simply with provision of physical safety, defined as the absence of aggression and the presence of affiliative intent. Physical aggression is toxic to intimacy (Lawrence \& Bradbury, 2007; Sullivan, Pasch, Lawrence, \& Bradbury, 2015) and the listener's ability to regulate potentially destructive 
RUNNING HEAD: INTIMATE RELATIONS

responses predicts relational well-being (Rusbult, Verette, Whitney, Slovik, \& Lipkus, 1991). In contrast, appropriate, responsive touch, such as a hug or pat on the back, can be a pivotal component of providing safety, especially in response to more intense, non-verbal expressions of emotion (Christophe \& Rimé, 1997; Schachner, Shaver, \& Mikulincer, 2005). Intimate partners are likely to seek responsive touch when in distress (Robinson, Hoplock, \& Cameron, 2015), likely because it improves emotional regulation (Coan, Schaefer, \& Davidson, 2006; Debrot, Schoebi, Perrez, \& Horn, 2014), perceptions of support (Robinson et al., 2015), positive affect and intimacy in both partners, and psychological well-being (Debrot, Schoebi, Perrez, \& Horn, 2013).

Safety is also conveyed through the listener's subtle, non-verbal indicators of attention to and engagement with the speaker. When a listener is inattentive and their natural responsiveness is suppressed or out of sync with the speaker, the listener fails to signal affiliative intent (Bourgeois \& Hess, 2008), and the speaker is more likely to experience threat rather than safety and dysregulate rather than stay socially engaged (Porges, 2011). For the speaker, this results in increased anxiety (Vicaria \& Dickens, 2016) and poorer self-disclosures (Bavelas, Coates, \& Johnson, 2000). In contrast, eye-contact, facial mimicry, and other non-verbal indicators of interest and attention during the social interaction (e.g., nodding) are key for successful interactions, improving closeness, trust, and empathy (Vicaria \& Dickens, 2016).

Verbal expressions (e.g., variations on the theme, "You are safe with me") can also function to convey safety (to the extent they are congruent and synchronized with non-verbal indicators). Likewise, simple verbal expressions of affiliative intent and affection (e.g., "I care about you," "I love you") may provide safety to appropriate others, especially under conditions of stress or threat. Such expressions have direct physiological benefits, predicting lower cortisol 
RUNNING HEAD: INTIMATE RELATIONS

levels (Floyd et al., 2007) and cortisol recovery after a stressful event (Floyd \& Riforgiate, 2008).

Consistent with other models such as the risk-regulation theory of intimate relationships (Murray, Holmes, \& Collins, 2006), reciprocally joining the speaker in vulnerability may also function to convey safety, signaling to the speaker that they will not be alone in taking risks towards intimacy and relational commitment (e.g., "I love you too"; Baxter \& Braithewaite, 2008; Harrison \& Shortall, 2011; Owen, 1987; Weigel, 2008). In fact, in the original fast friends procedure, participants engaged in reciprocal self-disclosures, with no other responsiveness required (Aron et al., 1997). The notion of reciprocity as essential in establishing trust as vulnerability increases also has been formulated by other researchers in terms of mutuality (Deci, La Guardia, Moller, Scheiner, \& Ryan, 2006) and supportive equity (Gleason, Iada, Bolger, \& Shrout, 2003).

\section{Verbal self-disclosure ("expressing yourself”) and validation}

The second and third sub-relations of our model focus on the verbal behavior that correspond with Skinner's (1957) early distinction between tacting and manding, which have demonstrated clinical utility with respect to effective communication training (e.g., for people with an ASD diagnosis; Sundberg \& Michael, 2001) and have retained a place in contemporary contextual-behavioral views of normative adult language (Barnes-Holmes, Barnes-Holmes, \& Cullinan, 2000). Tacts are verbalizations that primarily function to label or name things and require responses that function as agreement or validation, while mands are verbalizations of specific requests or needs and require responses that are idiosyncratic and specific to the nature of the request. For example, a tact is "That is a glass of water," responded to with, "Yes, that is glass of water," and a mand is "Can I have a glass of water?", responded to by giving the speaker 
RUNNING HEAD: INTIMATE RELATIONS

a glass of water. In our model, the second sub-relation of verbal self-disclosure and validation maps on to tacting, specifically describing and naming things relevant to one's self and selfexperience.

Verbal self-disclosure. Individuals must talk about themselves - their thoughts, feelings, memories, values, and identity — and this talk must be received with validation and understanding for intimate relationships to develop. Although most disclosures over the course of relationships are not be particularly vulnerable (e.g., small talk), an emphasis is placed on disclosures involving emotions and vulnerability, which are key drivers of intimacy in relationships (Ajzen \& Fishbein, 1977; Altman \& Taylor, 1973; Collins \& Miller, 1994).

A fundamental point is that the behaviors described by the first and second relations of our model need to sync'ed and congruent for intimacy to develop. In other words, selfdisclosures that involve and display emotional content enhance intimacy and feelings of support, while disclosure of facts and information that lack emotional content do not (Laurenceau et al., 1998; Shimanoff, 1988). Similarly, disclosures of personally significant autobiographical memories are the strongest predictors of intimacy enhancement (Alea \& Bluck, 2007). The emotional content of the disclosure and the congruence between what one is saying and showing likely is important as it helps the listener respond well: Congruence between what one is saying and what one is feeling predicts a listener's empathic accuracy (Lewis, Hodges, Laurent, Srivastava, \& Biancarosa, 2012) which in turn predicts relational well-being (Winczewski, Bowen, \& Collins, 2016).

Distinguishing between verbal self-disclosures of negative events/emotions and positive events/emotions may also be clinically and scientifically useful. Regarding negative events, it is clear that self-disclosure of negative emotional content is crucial to the deepening of 
RUNNING HEAD: INTIMATE RELATIONS

relationships (Graham, Huang, Clark, \& Helgeson, 2008; Nils \& Rimé, 2012; Zech \& Rimé, 2005) but is indeed a vulnerable thing to do, in that there is real risk that the disclosure will not be accepted and will result in interpersonal punishment of some kind (Cordova \& Scott, 2001).

For example, the way in which one discloses predicts whether the disclosure will result in relational distancing rather than closeness. As reviewed by Baddeley and Singer (2009), disclosures that display a pre-occupation with one's own suffering or dwell on failed goals without any indication of pursuit of new goals are less likely to lead to acceptance and more likely to lead to social awkwardness in listeners. Particularly vulnerable stories that display these features undoubtedly require a close, trusted confidant (Alea \& Bluck, 2003), and even then, indiscriminate and repetitive expression of negative mood in this fashion likely will result in decreased intimacy and likeability and increased interpersonal problems over time (e.g., Coyne, 1976; Marcus \& Nardone, 1992; Segrin \& Abramson, 1994). Curci and Rimé (2012) identified a subset of individuals who get caught in a reinforcing cycle, analogous to mental rumination, in which disclosure of negative events is experienced as repetitive ventilation and potentially toxic to relationships over time, but the behavior persists due to short-term distress reduction benefits. Individuals who are pre-disposed to feeling negative emotions strongly (i.e., high on negative affectivity; Watson \& Clark, 1984), may likely exhibit this pattern (Kennedy-Moore \& Watson, 2001), and listeners are likely to discount their disclosures and respond poorly or not at all when this happen (Forest, Kille, Wood, \& Holmes, 2014).

Clinicians are often focused on negative events and negative affect, but disclosures of positive events are surprisingly important to the development of intimacy. Argyle and Henderson (1984) identified the social sharing of positive events as highly important within friendships, but similar processes are observed with romantic partners as well (Logan \& Cobb, 2013). Langston 
RUNNING HEAD: INTIMATE RELATIONS

(1994) described the process of sharing positive events with others as one of capitalization. Specifically, while a positive event has an independent effect on mood, one may capitalize on that event, bringing additional benefits by sharing it with others such as improved daily relationship satisfaction, intimacy, and relational well-being (Gable et al., 2006; Gable, Reis, Impett, \& Asher, 2004). Strong responses to positive events predict later perceived responsiveness to negative events and are more predictive of later intimacy than are responses to negative events (Gable, Gosnell, Maisel, \& Strachman, 2012). Furthermore, sharing positive events with others, especially friends, may enhance the positive affective experience of that event (Reis, O’Keefe, \& Lane, 2017).

Validation. "Validation" describes the functional response to vulnerable self-disclosures in our model. Our emphasis on the term "validation" is consistent with clinical models of validation, including models of empathic understanding as per client-centered therapy (e.g., Rogers, 1951) and Linehan's (1993) Dialectical Behavior Therapy. Specifically, validation involves expressing that you understand the deeper meaning of other person's communication. As discussed below, keys to expressing understanding of the deeper meaning are validating the emotional content and providing emotional support, and validating relevant aspects of identity.

Just as vulnerable self-disclosure builds on and incorporates non-verbal emotional expression, the listener's provision of validation, which is primarily a verbal response, builds on and incorporates provision of safety. Reciprocity, briefly considered above as a means of conveying safety by joining the speaker in the vulnerability, is functionally relevant to validation as well. For example, it is natural in developing relationships, particularly early in these relationships, for a listener's primary response to a speaker's self-disclosure to be an immediate, reciprocal, related disclosure (Morton, 1978; Sprecher \& Treger, 2015). The degree to which a 
RUNNING HEAD: INTIMATE RELATIONS

reciprocal disclosure is experienced as validating depends on the degree to which it is congruent with the speaker's emotional state, motivated by empathic concern (Winczewski et al., 2016), not excessively negative (Forest et al., 2014), and not experienced by the speaker as undermining or trivializing their disclosure or "stealing" the narrative (Alea \& Bluck, 2003).

Central to validation is that it is experienced as providing emotional support (i.e., empathy and understanding), often distinguished in the social support literature from instrumental (sometimes called practical or informational) support (i.e., offering help and advice; Cutrona, Shaffer, Wesner, \& Gardner, 2007; Feeney \& Collins, 2015; Helgeson, 1993; House et al., 1988; Morelli, Lee, Arnn, \& Zaki, 2015; Shrout, Herman, \& Bolger, 2006; Suhr, Cutrona, Krebs, \& Jensen, 2004). This distinction between emotional and instrumental support is central to our model's distinction between the current validation response to vulnerable selfdisclosure and the subsequent giving response to asking.

Listeners are likely to make the mistake of providing instrumental support and advice when the speaker is seeking emotional support. Coyne, Wortman, and Lehman (1988) documented that many well-intentioned support attempts, focusing on problem solving and advice rather than emotional support, fail to meet the needs of those under stress and may make matters worse. The speaker may not be ready to analyze the situation in a cognitive fashion and the listener may not have enough information to offer anything but overly simplistic reappraisals, which are not experienced as helpful by the speaker, especially in initial sharing situations (Rimé, 2009). Yet some studies have found that bids for emotional support are more likely to be followed by unsolicited advice than by any other response (Cutrona et al., 2007). Listener responses that discriminate the speaker's specific emotional versus instrumental needs are more effective at increasing relational closeness. For example, matching support, 


\section{RUNNING HEAD: INTIMATE RELATIONS}

defined as responding to a disclosure of emotions with emotional rather than instrumental support, predicts higher relational satisfaction and relational willingness in the discloser, while mismatched support predicts lower satisfaction and willingness (Cutrona et al., 2007; Horowitz et al., 2001). The importance of matching the response to the speaker's emotional support needs increases as the vulnerability of the speaker's disclosure increases. For example, in the context of disclosures of grief or other major losses, accurate empathy and validation are crucial and unsolicited advice may be harmful to the relationship (Dyregrov, 2003; Lehman, Ellard, \& Wortman, 1986). Unsupportive listener responses to speakers experiencing and disclosing significant negative life events are not neutral but are harmful physically and psychologically (Ingram, Betz, Mindes, Schmitt, \& Smith, 2001).

Research on self-verification theory (Swann, 1990) also provides insights on how to be maximally validating as a listener. According to this theory, a speaker engaging in vulnerable self-disclosure is an important opportunity for the listener to present feedback that verifies the speaker's self-conceptions and identity, which has been shown in multiple studies to contribute to relational well-being (reviewed in North \& Swann, 2009). Self-verification theory makes the important prediction that validation of the self is more important than positivity; when individuals receive responses from relational partners that are overly positive and not consistent with how they see themselves, individuals seek relational distance and intimacy suffers. At the same time, repeatedly validating the negative self-relevant thoughts and feelings of a partner may worsen or maintain those beliefs (Pettit \& Joiner, 2001) which, if the pattern becomes rigid and chronic, can lead the listener to seek distance (Segrin \& Abramson, 1994). 
RUNNING HEAD: INTIMATE RELATIONS

\section{Asking and giving}

In our model, the broad and multi-faceted domain of expressing and negotiating needs in relationships and receiving responsive support is framed as asking and giving. This asking-giving relation is distinguished from the self-disclosure-validation relation as instrumental support is distinguished from emotional support, and in behavioral terms, as mands are distinguished from tacts. Asking, in behavior-analytic terms, is manding.

Asking. Asking builds on the previous speaker behaviors of non-verbal vulnerable emotional expression and self-disclosure. If the goal is to maintain relational closeness in the process, versus simply gaining one's objective regardless of relational cost, then asking may be a difficult process that subsumes vulnerable self-disclosure. This is for multiple reasons. First, selfdisclosing to the listener the vulnerable need motivating a specific request is seen as a fundamental, preliminary element of effective "asking” repertoires (e.g., Linehan, 2014), and Morelli et al. (2015) found that instrumental support provision was only beneficial to relational well-being when it co-occurred with emotional validation. In addition, the speaker may fear that the expression or request will lead to conflict and rejection and may manage these fears by not making the request, or by making it indirectly in a way that is difficult to perceive and support (Murray et al., 2006). Such fears of rejection when making one's needs known are particularly salient and likely to produce avoidance for individuals with lower self-esteem (Marigold, Cavallo, Holmes, \& Wood, 2014; Murray et al., 2006) or insecure attachment styles (Beck \& Clark, 2009). Finally, when asking for what one needs, speakers may have additional concerns about becoming indebted to the listener or experiencing the potential help given as a threat to one's self-reliance or autonomy (Nadler, 2015). 
RUNNING HEAD: INTIMATE RELATIONS

Asking includes requests related to both non-relational and relational needs, which maximize well-being when collectively satisfied (Ryan \& Deci, 2000). Non-relational needs that are negotiated in relationships range from major issues (e.g., a change of a job that will affect the partner's lifestyle) to relatively minor issues (e.g., needing a regular exercise schedule). Expressing, negotiating, and asking for help with these non-relational needs predicts relational closeness and relational well-being (e.g., Deci et al., 2006; Fitzsimons \& Shah, 2008; Koestner, Powers, Carbonneau, Milyavskaya, \& Chua, 2012; Molden, Lucas, Finkel, Kumashiro, \& Rusbult, 2009), inoculates the partners against the negative effects of relational disagreements (Knee, Lonsbary, Canevello, \& Patrick, 2005; Patrick, Knee, Canevello, \& Lonsbary, 2007), and increases the likelihood of partner's providing reciprocal responsiveness in the future (Deci et al., 2006).

Relational needs and requests of all forms also must be negotiated in relationships, from the trivial (where to go for dinner) to the profound (whether to have a child). Such asking has received considerable attention under the framework of assertiveness training, typically defined as making specific requests of others, refusal skills, and setting limits in a manner that is nonaggressive, clear, and effective (e.g., Duckworth, 2009). Improving assertiveness skills in one partner has been shown to improve relational well-being and closeness for both members of the couple (Gordon \& Waldo, 1984), and assertiveness in various guises is a common element of evidence-based couple’s therapy interventions (Christensen \& Heavey, 1999).

Giving. We label the functional response to asking as giving, which involves providing an empathically accurate and tailored response. A substantial literature relevant to giving is on instrumental support, and this literature suggests that it is not straightforward. Specifically, support provided in obvious, visible ways may undermine the speaker's self-efficacy, increase 
RUNNING HEAD: INTIMATE RELATIONS

their doubts about their competence in the problem domain, increase their perception that their distress and incompetence are publicly visible, all of which can produce downstream effects on the speaker's emotional distress (Bolger \& Amarel, 2007; Bolger, Zuckerman, \& Kessler, 2000; Gleason et al., 2003; Gleason, Iida, Shrout, \& Bolger, 2008; McClure et al., 2014). All of this underscores the vulnerability inherent in asking, as the response may be damaging in multiple ways.

Sometimes one may give too much, or give insensitively. Kappes and Shrout (2011) found that excessive unsolicited advice (rather than waiting to be asked for help by the speaker) produces decreases in task performance and relational quality. Likewise, Koestner et al., (2012) found that support from a listener that prioritizes the speaker's autonomy predicts both the speaker's goal progress and reported relational quality, while overly directive support predicts goal progress but not relational quality. Importantly, the provision of effective autonomy support predicts relational quality and closeness for both the giver and the asker (an effect which may be stronger for the giver; Deci et al., 2006). Similarly, too much responsiveness, when the speaker is displaying a milder level of distress, also is experienced as unresponsive (Girme, Overall, \& Simpson, 2013).

Thus, the most effective giving responses are subtle and attuned to the speaker's needs for autonomy, efficacy and competence (Bolger et al., 2000; Bolger \& Amarel, 2007). When responses are perceived as responsive, the problems associated with visible support are eliminated (Cavallo, Zee, \& Higgins, 2016; Maisel \& Gable, 2009). In other words, the problem with visible support is not that it is visible, but that it is not tailored to and validating of the speaker's emotional and motivational state. As such, giving builds on validation. Bolger and colleagues also note that obvious and visible support provision may create a sense of 
RUNNING HEAD: INTIMATE RELATIONS

indebtedness or relational inequity, and this can be mitigated if the support provider also reciprocally occupies the role of the vulnerable support recipient at times.

Giving is easy in theory but difficult in practice. Sometimes, for example, what is asked for by the speaker, or at least is needed if not directly requested, is for the listener to offer an apology and to take responsibility for a transgression; or vice versa, sometimes it is the transgressor asking the other for forgiveness, both of which, when offered genuinely, are important to relational and personal well-being, but both of which are hard to do well (Bono, McCullough, \& Root, 2008; Hodgins \& Liebeskind, 2003).

Relatedly, in long-term relationships there are multiple times when the speaker's request conflicts with the listener's needs (Rusbult \& Van Lange, 1996; Simpson, 2007). Such conflicts are some of the most difficult moments in relationships and may be the stimulus for couple's therapy. In these situations, support may not be given at all or is given grudgingly or in an insulting manner that may be detrimental to both parties (Coyne et al., 1988). In contrast, genuinely giving what a speaker needs, in a situation in which the giver could have acted in their own self-interest, is particularly important in communicating commitment to the relationship and bolsters the speaker's trust in and feelings of closeness to the giver (Weiselquist, Rusbult, Foster, \& Agnew, 1999). Important to successful giving in these complex relational dynamics is the establishment of reciprocity in responsiveness over time (Canevello \& Crocker, 2010; Weiselquist et al., 1999), which also has been formulated in terms of mutuality (Deci et al., 2006; Murray et al., 2006) or supportive equity (Gleason et al., 2003). Reciprocity over time is not equivalent to tallying and keeping track of accounts; in fact, doing this can undermine responsiveness, as support may be perceived as a settling of accounts or accrual of obligations rather than as caring (Clark, Mills, \& Powell, 1986; Clark \& Monin, 2006). Rather, reciprocity 
RUNNING HEAD: INTIMATE RELATIONS

refers to exchanges of asking and giving that balance naturally over the course of the relationship.

\section{Expressions of closeness}

Although any verbal expression may have multiple functions, expressions of closeness (e.g., "I love you," "I feel close to you," "You are so important to me,") are particularly complex. Nevertheless, as discussed below, they are seen as quintessential to the intimacy process. Such expressions at times may function as vulnerable self-disclosures (Turn 1 of the model), representing an explicit proclamation of one's feelings towards the other and one's commitment intentions, providing the listener an explicit and decisive moment to reject the speaker or advance the relationship (Baxter \& Braithewaite, 2008; Harrison \& Shortall, 2011; Owen, 1987; Weigel, 2008). Expressions of closeness may also function as asking — as bid for reciprocal disclosures of feeling (at Turn 1) or as a means of conveying safety and validation (at Turn 2). Similarly, such expressions also can function as giving if they are responses to specific bids for reciprocity (akin to a hidden mand). Overall, the experience of vulnerability that attends such expressions may be quite salient for the speaker who initiates the dialogue as well as for the listener who may be unprepared for the disclosure and is unexpectedly in a position to reciprocate (Ackerman, Griskevicius, \& Li, 2011; Blomquist \& Giuliano, 2012).

Expressions of closeness also include conveying the private experience of perceived responsiveness (considered below under "Awareness") back to the listener (e.g., "I feel cared for by you"), which in our view is a particularly vulnerable and crucial aspect of intimate interactions. From a contextual-behavioral perspective, this moment serves as a reinforcing response to the listener's provision of responsiveness. In support of this idea, Grant and Gino (2010) found that when a listener provides assistance in response to a request from a speaker 
RUNNING HEAD: INTIMATE RELATIONS

(i.e., giving), expressions of gratitude from the speaker directly increase the likelihood the listener will respond similarly in the future, an effect that may be mediated by the listener's sense of being valued by the speaker. Likewise, the listener's experience of closeness with the speaker is directly associated with the degree to which they believe the speaker perceives their enacted response as responsive (Debrot et al., 2012). Expressions of appreciation and gratitude also increase future responsiveness of both partners and increase partner's sense of commitment and likelihood of maintaining the intimate relationship over time (Gordon, Impett, Kogan, Oveis, \& Keltner, 2012).

\section{Awareness}

We consider the relations described above to be functional relations because the listener behaviors that are described as responses to the speaker behaviors are reinforcing (and in the final case of expressions of closeness, the speaker behavior is reinforcing of the listener behavior). For a full description of a functional relation, however, the antecedents that provide the appropriate context for these behavior-response relations also need to be described. Here, we address this issue with our final term, awareness. We consider awareness as an issue of discrimination, increasing contact with and salience of the key antecedent stimulus conditions that maximize successful interpersonal behavior.

The original IPM did not describe antecedents per se but did discuss motivational variables, specifically that speakers' and listeners' behaviors and perceptions are influenced by their motives, needs, goals and fears. We re-formulate these constructs as awareness to clarify potentially modifiable psychological processes necessary for effective behavior in the moment of the interaction. Three modes of awareness are described: self-awareness (e.g., of one's feelings and needs), other-awareness (e.g., perspective taking and empathy for the other individual in the 


\section{RUNNING HEAD: INTIMATE RELATIONS}

interaction), and contextual-awareness (e.g., awareness of situational influences). Although there is considerable overlap and all three modes are relevant to both the speaker and the listener, it is likely that the relative importance of different modes of awareness varies. For most speakers, self-awareness may be most important while for most listeners, other-awareness may be most important.

Self-awareness. Self-awareness is fundamental to engaging in vulnerable self-disclosure as described by our model. Being aware of one's needs and feelings increases the likelihood that one will communicate those needs and feelings effectively (Cordova, Gee, \& Warren, 2005; Saxena \& Mehrotra, 2010; Wachs \& Cordova, 2007). Self-awareness of what one is feeling, however, is not sufficient without important qualifications, as increased awareness of aversive and vulnerable feelings is likely to lead to avoiding rather than approaching intimacy. As discussed throughout this paper, intimate relating is an inherently vulnerable process, with two individuals exposing themselves to the possibility of being hurt by each other (Leary \& Carrie, 2001) and trusting each other not to do so (Simpson, 2007). Negotiating natural tendencies to avoid vulnerability and risk with the desire for closeness is a fundamental task in relationship formation (Murray et al., 2006). Thus, some degree of avoidance of or at least ambivalence around the vulnerable emotions inherent in intimate relating is normative, and for some individuals, avoidance in response to this potential vulnerability may be a substantial obstacle. For example, individuals with high social anxiety (Kashdan, Volkmann, Breen, \& Han, 2007), who fear intimacy (Descutner \& Thelen, 1991; Doi \& Thelen, 1993), or who demonstrate avoidant attachment (Mikulincer, Shaver, Bar-On, \& Ein-Dor, 2010) all are reluctant to selfdisclose and have relational problems as a result. Expressing vulnerabilities will be particularly perilous for these individuals and they may regulate this risk in interpersonally problematic ways 
RUNNING HEAD: INTIMATE RELATIONS

such as avoiding altogether (Murray et al., 2006) or excessively seeking reassurance (Joiner \& Metalsky, 2001).

Thus, the task is not simply awareness of vulnerable feelings but awareness infused with acceptance of and willingness to experience vulnerability in the service of intimacy. In other words, the primary mindfulness and acceptance processes described by Acceptance and Commitment Therapy (ACT; Hayes, Follette, \& Linehan, 2004) are fundamental to the experience of awareness that is described here. We subscribe to a behaviorally oriented definition of mindfulness as a psychological process - something people do - consistent with Kabat-Zinn's (2009, p. 4) definition: "Paying attention in a particular way: on purpose, in the present moment, and nonjudgmentally," with attention typically but not exclusively focused on one's private experiences (i.e., feelings, thoughts, sensations). Likewise, acceptance is defined as "actively contacting psychological experiences — directly, fully, and without needless defense" (Hayes et al., 1996, p. 1163). Acceptance sits on the positive end of a continuum with avoidance, which involves an unwillingness "to remain in contact with particular private experiences (e.g., bodily sensations, emotions, thoughts, memories, behavioral predispositions) and [to take] steps to alter the form or frequency of these events and the contexts that occasion them" (p. 1154).

Several lines of research support the importance of such mindful, accepting awareness in the interpersonal process. In the context of vulnerable feelings that naturally arise in intimate interactions, mindful, accepting awareness of one's own emotions improves emotion regulation and decreases emotional interference, physiological reactivity, and negative cognitive reappraisals of the emotion and the emotion-triggering events (Hölzel et al., 2011), all of which may contribute to more effective relational functioning (Atkinson, 2013). Mindfulness decreases emotional suppression and improves emotional clarity and expression in day-to-day interactions 
RUNNING HEAD: INTIMATE RELATIONS

(Keng, Smoski, \& Robins, 2011; Saxena \& Mehrotra, 2010), in intimate couples (Wachs \& Cordova, 2007), and in social interactions in general (Jazaieri et al., 2014), especially in socially threatening situations (Heppner et al., 2008). Fredrickson, Cohn, Coffey, Pek, and Finkel (2008) found that loving-kindness meditation in particular increases clarity about positive emotions and has several benefits that include improved expression to and relating with others. Couple's therapy interventions often include interventions to not only increase emotional and vulnerable expression but to increase the accuracy of perceptual judgments of the others' expressions (Benson, McGinn, \& Christensen, 2012), and mindfulness training in couples has been shown to improve relational quality (Carson, Carson, Gil, \& Baucom, 2004).

While vulnerable self-disclosure may occur at Turn 1 of the process, crucially it also may occur at Turn 3, with the original speaker responding to the listener's Turn 2 response with an expression of closeness. Mindful, accepting awareness is important for success at both moments, and the Turn 3 response is a key moment for intimacy in which the proposed central organizing principle of relationship science - perceived partner responsiveness - comes into play for a speaker. In this moment, after the listener has responded to the speaker in an intimate and responsive way, the speaker is tasked with recognizing and accepting their own vulnerable feelings, overcoming urges to distance from the listener out of avoidance, recognizing and defusing from negative perceptual biases, and expressing closeness or appreciation as reinforcement for the listener.

Individuals who demonstrate problems with vulnerability around self-disclosure (e.g., people with social anxiety, high fear of intimacy) also demonstrate problems perceiving the enacted response as responsive (Beck \& Clark, 2009; Collins \& Feeney, 2004; Emmons \& Colby, 1995; Gosnell \& Gable, 2013; Heerey \& Kring, 2007; Kashdan, Ferssizidis, Farmer, 
RUNNING HEAD: INTIMATE RELATIONS

Adams, \& McKnight, 2013; Marigold et al., 2014; Mendlowicz \& Stein, 2000). While these findings are typically interpreted as resulting from immutable dispositional traits (e.g., attachment styles), we suggest a more proximal, mutable mechanism: experiential avoidance of indicators of attachment and closeness from others because it is threatening and aversive to do otherwise.

Thus, PPR may be construed as a psychological process of mindful, accepting selfawareness of vulnerability and those who report lower levels of PPR may be experiencing their partner's responses as threatening or otherwise aversive and thus may benefit from interventions focusing on mindful, accepting self-awareness. While PPR is typically defined as a perceptual process, it is not clear how to target and improve perceptual processes. On the other hand, as is well known within the CBS community, existing CBS interventions that target avoidanceacceptance are clearly articulated (e.g., Hayes, Follette, \& Linehan, 2004), have a clear evidence base (Levin, Hildebrandt, Lillis, \& Hayes, 2012), and may be tailored and evaluated in the context of intimate relationships.

Other awareness. Mindful, accepting, self-awareness and emotional clarity are not sufficient to optimize intimate interactions; it is also important to be aware of the other in the interaction. For example, when a speaker expresses interpersonal vulnerabilities and insecurities to others, the speaker may become pre-occupied by their own vulnerability, leading to doubts that the listener will respond authentically and inaccurate appraisals of the listener's actual response to the disclosure (Lemay \& Clark, 2008). This balancing of self-awareness and otherawareness for the speaker may be particularly important for those who are prone to inaccurately perceiving others. For example, individuals who are high in attachment insecurity (e.g., Overall, Fletcher, Simpson, \& Fillo, 2015; Simpson, Rholes, \& Phillips, 1996) or rejection sensitivity 
RUNNING HEAD: INTIMATE RELATIONS

(Downey \& Feldman, 1996) or low in self-esteem (Murray, Holmes, \& Griffin, 2000)

underestimate their others' regard for them, perceive their partners as less responsive to or more rejecting of them than they actually are, and experience their relationships as less satisfying. Similarly, socially anxious individuals report poor outcomes when they engage in emotional disclosures (Kashdan, et al., 2007), an effect that may result from a preoccupation with experienced anxiety that influences how the listener's response is perceived.

Awareness of what the other is feeling and experiencing is particularly important for the listener who is responding to the speaker's disclosures. For example, the two related constructs of empathy and perspective taking are seen as fundamental to promotion of prosocial behavior in general (Batson, Lishner, \& Stocks, 2015) and relational quality in particular (Cramer \& Jowett, 2010; Davis \& Oathout, 1987; Long \& Andrews, 1990; Schröder-Abé, \& Schütz, 2011), and feature prominently in interventions for those with social deficits such as Autism Spectrum Disorder (e.g., Golan \& Baron-Cohen, 2006).

Particularly important is the listener's accurate attunement to and understanding of the speaker's feelings and needs, or empathic accuracy (Ickes, 1997), which predicts responsiveness and relational closeness (Winczewski et al., 2016), improved support provision (Neff \& Karney, 2005; Verhofstadt, Buysse, Ickes, Davis, \& Devoldre, 2008), and a lower likelihood of divorce (Neff \& Karney, 2005). Without empathic accuracy, the responsiveness attempts of even wellintentioned individuals may be perceived as insincere, insensitive or out of sync with the discloser's goals and needs (Reis \& Gable, 2015). A fundamental task of empathic accuracy, when listening to a speaker, may be discriminating the speaker's need for emotional versus instrumental support (Cutrona, 1990; Cutrona et al., 2007). 
RUNNING HEAD: INTIMATE RELATIONS

Contextual awareness. Finally, the speaker and listener must be aware of the relevant features of the situational and relational context in which the interaction takes place. For example, the degree to which the listener will respond to the speaker's emotional expressiveness depends on which emotion is expressed, the nature of the relationship, the length of the interaction, and how costly responding will be for the listener (reviewed by Bourgeois \& Hess, 2008). Expressions of happiness, for example, are likely to be reciprocated across contexts, but listeners may respond poorly to expressions of sadness if the emotion is intense, if the relationship is not close, if there is not time for an extended interaction, and if the response will be emotionally costly. Similarly, as discussed above, it is clear that engaging in emotional selfdisclosure increases the intimacy of the relationship, but this only holds true for ongoing relationships, and may backfire with strangers who will find the self-disclosure socially inappropriate (Collins \& Miller, 1994). Likewise, vulnerable disclosures made by higher-status individuals (e.g., managers) in work and organizational contexts undermine task-oriented relationships and hurt relational quality, while disclosures among equal status peers are beneficial (Gibson, Harari, \& Marr, 2018). The speaker, therefore, will benefit from awareness of these contextual features to maximize the probability that the expression will be responded to well and enhance relational quality.

\section{Considerations}

The simple linear sequence (Turn 1, Turn 2, Turn 3...) depicted in our model is for the purpose of creating a useful model to guide research and practice. Natural interactions, however, are more dynamic and functionally complex than that which is depicted in Figure 2. As emphasized in our discussion of expressions of closeness, a given response may serve multiple functions (sometimes simultaneously). Thus, our model is not intended to imply that there is a 
RUNNING HEAD: INTIMATE RELATIONS

one-to-one correspondence between the utterances of the speaker and the listener in a natural interaction and the specific terms of our model. Rather, our model predicts and hopefully clarifies certain important functional sequences that may occur amidst the complexity of natural interactions. We refer to these sequences as "highly probable" in the development of closeness.

Another consideration is that the actual content or form of a response is not always a reliable guide to its function. For example, we suggest that the expression of closeness, "I love you," primarily functions to reinforce one's responsiveness and also as a vulnerable selfdisclosure; however, it also can function as a specific request (i.e., asking) or a response to such a request (i.e., giving). In fact, we emphasize multiple responses with functions that are not clear from the form (i.e., topography) alone. What appears to be a self-disclosure (i.e., a tact; "I'm tired") functionally may be an implicit request made by a partner who lacks strong explicit asking skills (e.g., the person really means to ask, "Can we go home now?”). These are known as "disguised mands" in the behavior analysis literature (e.g., Najdowski, Bergstrom, Tarbox, \& Clair, 2017). Although it would benefit the speaker to be more direct, in the moment the listener would benefit from strong awareness skills (specifically, empathic accuracy) to respond well.

As another example, according to self-verification theory (Swann, 1990), a simple response of praise from the listener (e.g., "I think you look beautiful") to a vulnerable selfdisclosure (e.g., "I feel ugly") may look validating on the surface but not function as validation if it does not reflect the speaker's self-concept. Similarly, a clear response from the listener ("Fine, let's go home") to a specific request may not function as giving if it is provided in an obvious way that is experienced by the speaker as undermining their self-efficacy (Maisel \& Gable, 2009). Likewise, reciprocal responding, which ideally is an intimacy-enhancing response that conveys safety and validation, is functionally complex. For example, a self-disclosure from the 
RUNNING HEAD: INTIMATE RELATIONS

listener in response to a self-disclosure from the speaker may be an effective means of providing safety and validation because it also functioned as a vulnerable disclosure from the listener. Conversely, it may be punishing and invalidating of the speaker to the extent that it was experienced as stealing the narrative or only minimally responsive to the original disclosure.

Finally, the temporal sequence suggested by the model likely is more complex than is depicted in Figure 2. For example, the speaker's self-disclosure may unfold over several conversational turns, with interruptions, interjections, questions, reciprocal disclosures, or other responses from the listener that are cumulatively experienced as validating by the speaker (along with multiple other possible reactions). Likewise, expressions of closeness in response to the listener's response may occur only partially and much later in the turn-by-turn sequence, or perhaps at a separate time altogether. Nonetheless, a general functional understanding of these interactions is useful, replicates across a variety of research paradigms, and suggests that reinforcement is a cumulative process within- and between-interactions. When these dyadic interactions go well, to the extent that both persons' responses are cumulatively experienced as reinforcing, both the speaker and the listener will be more likely to engage in the interactions again. Over time, in most relationships, this will occur reciprocally, in that both members of the dyad engage in vulnerability, responsiveness, and expressions of closeness, shaping each other towards deeper levels of intimacy.

\section{Research Directions}

Research suggests that there may be important heterogeneity across groups - e.g., gender, ethnicity, culture, and sexual identity - in the processes described throughout this paper (e.g., Butler, Lee, \& Gross, 2007; Chen, Kim, Sherman, \& Hashimoto, 2015; Marshall, 2008). It is important to not overstate the universal applicability of the model without taking various cultural 
RUNNING HEAD: INTIMATE RELATIONS

and identity considerations into account and to recognize that most of the research reviewed herein was conducted with predominantly WEIRD (Western, Educated, Industrialized, Rich, Democratic) samples. These are important areas for future development and evaluation of the model.

Furthermore, although the model represents an integrative review of many welldocumented research findings, the full model as a whole has not been experimentally evaluated. For example, how the specifically defined functional processes of the model combine or interact to influence intimacy outcomes has been evaluated only in preliminary form (Haworth et al., 2015; Manbeck et al., in press). In our view, it is important to pursue both basic research and applied intervention development and to determine whether this model provides benefit in terms of dissemination and implementation in various settings of public health significance. Preliminary applications of the model have shown promise (Kanter et al., 2018; Kanter et al., 2013; Kohlenberg et al., 2015; Reyes Ortega et al., 2019), and currently we are developing and evaluating psychotherapy applications within a FAP framework to help individuals who struggle with intimate relational functioning (see Maitland et al., 2017), to improve inter-racial communication and decrease racial bias (Kanter, Corey, Manbeck, \& Rosen, 2019), and to improve dialogue between liberals and conservatives in the United States (Manbeck et al., 2018). To date, however, there is no evidence that the full model represents an empirical improvement over the IPM as a vehicle for intervention efforts. These are fruitful avenues for researchers to explore.

Our review focused on the interactional processes that occur in intimate relationships but only touched on how individuals learn and apply the skills necessary for this process to go well. For example, it is known that attachment dynamics in early development influence later 
RUNNING HEAD: INTIMATE RELATIONS

attachment styles, with direct implications for intimate relating (Reis \& Patrick, 1996), including influencing the nature of vulnerable emotional expression (Mikulincer et al., 2010), enacted responsiveness (Feeney \& Collins, 2001), and perceptions of responsiveness (Collins \& Feeney, 2004). Likewise, much is known about the development of empathy (Eisenberg, Spinrad, \& Knafo-Noam, 2015), a key driver of enacted responsiveness. That said, continued longitudinal and developmental research may shed light on how the important processes and relations emerge and are learned, if there are sensitive periods for such learning (Knudsen, 2004), and how processes may become disordered. Such research may inform intervention efforts designed to teach these skills to individuals and dyads.

\section{Conclusion}

Relationship science is a vast, productive, and clinically relevant field, with potential to produce interventions that impact some of our most significant public health problems. Yet, to date, CBS has not taken this science into consideration, and opportunities to capitalize on the strengths of CBS as a pragmatic, outcome-oriented science have been lost. The current review and model builds on core findings from relationship science, particularly the IPM and Reis' (2007) proposal of perceived partner responsiveness as a central organizing principle, to produce a CBS model of intimate relationships that can serve as the basis for CBS research and intervention development. We integrated converging research findings from multiple domains into a reformulation and expansion of the IPM's key processes, producing a set of behavioral, action-oriented, middle-level terms, with functional relations as their basis, to facilitate mainstream scientific investigation and real-world applications of the model. Our hope is that such model-building may spur basic and applied CBS research that maximizes the promise of relationship science and the potential of CBS to help with a fundamental task of being human, 
RUNNING HEAD: INTIMATE RELATIONS

that of forming and maintaining close relationships with each other as we collectively face our futures and the world's problems. 
RUNNING HEAD: INTIMATE RELATIONS

\section{References}

Ackerman, J. M., Griskevicius, V., \& Li, N. P. (2011). Let's get serious: Communicating commitment in romantic relationships. Journal of Personality and Social Psychology, 100(6), 1079-1094. https://doi.org/10.1037/a0022412

Ajzen, I., \& Fishbein, M. (1977). Attitude-behavior relations: A theoretical analysis and review of empirical research. Psychological Bulletin, 84(5), 888-918. https://doi.org/10.1037/0033-2909.84.5.888

Alea, N., \& Bluck, S. (2003). Why are you telling me that? A conceptual model of the social function of autobiographical memory. Memory, 11, 165-178. https://doi.org/10.1080/741938207

Alea, N., \& Bluck, S. (2007). I'll keep you in mind: The intimacy function of autobiographical memory. Applied Cognitive Psychology, 21, 1091-1111. https://doi.org/10.1002/acp.1316

Altman, I., \& Taylor, D. A. (1973). Social penetration: The development of interpersonal relationships. Oxford, England: Holt, Rinehart \& Winston.

Argyle, M., \& Henderson, M. (1984). The rules of friendship. Journal of Social and Personal Relationships, 1, 211-237. https://doi.org/10.1177/0265407584012005

Aron, A., Melinat, E., Aron, E. N., Vallone, R. D., \& Bator, R. J. (1997). The experimental generation of interpersonal closeness: A procedure and some preliminary findings. Personality and Social Psychology Bulletin, 23(4), 363-377. https://doi.org/10.1177/0146167297234003 
RUNNING HEAD: INTIMATE RELATIONS

Atkinson, B. J. (2013). Mindfulness training and the cultivation of secure, satisfying couple relationships. Couple and Family Psychology: Research and Practice, 2(2), 73-94. https://doi.org/10.1037/cfp0000002

Baddeley, J. L., \& Singer, J. A. (2009). A social interactional model of bereavement narrative disclosure. Review of General Psychology, 13, 202-218.

https://doi.org/10.1037/a0015655

Baer, D. M., Wolf, M. M., \& Risley, T. R. (1968). Some current dimensions of applied behavior analysis. Journal of Applied Behavior Analysis, 1(1), 91-97. https://doi.org/10.1901/jaba.1968.1-91

Barnes-Holmes, D., Barnes-Holmes, Y., \& Cullinan, V. (2000). Relational frame theory and Skinner's Verbal Behavior: A possible synthesis. The Behavior Analyst, 23(1), 69-84. https://doi.org/10.1007/BF03392000

Batson, C. D., Lishner, D. A., \& Stocks, E. L. (2015). The Empathy-Altruism Hypothesis. In Schroeder, D. A., \& Graziano, W. G. (Eds.), The Oxford handbook of prosocial behavior (pp. 259-268) Oxford, United Kingdom: The Oxford University Press.

Bavelas, J. B., Coates, L., \& Johnson, T. (2000). Listeners as co-narrators. Journal of Personality and Social Psychology, 79(6), 941-952. https://doi.org/10.1037/0022-3514.79.6.941

Baxter, L., \& Braithewaite, D. (2008). Engaging theories in interpersonal communication: Multiple perspectives. Thousand Oaks, CA: Sage. https://doi.org/10.1111/j.14602466.2009.01467.x

Beck, L. A., \& Clark, M. S. (2009). Choosing to enter or avoid diagnostic social situations. Psychological Science, 20(9), 1175-1181. https://doi.org/10.1111/j.14679280.2009.02420. 
RUNNING HEAD: INTIMATE RELATIONS

Benson, L. A., McGinn, M. M., \& Christensen, A. (2012). Common principles of couple therapy. Behavior Therapy, 43(1), 25-35. https://doi.org/10.1016/j.beth.2010.12.00

Blomquist, B. A., \& Giuliano, T. A. (2012). Do You Love Me, Too? Perceptions of Responses to I Love You. North American Journal of Psychology, 14(2), 407-418.

Bolger, N., \& Amarel, D. (2007). Effects of social support visibility on adjustment to stress: Experimental evidence. Journal of Personality and Social Psychology, 92, 458-475. https://doi.org/10.1037/0022-3514.92.3.458

Bolger, N., Zuckerman, A., \& Kessler, R. C. (2000). Invisible support and adjustment to stress. Journal of Personality and Social Psychology, 79, 953-961. https://doi.org/10.1037/00223514.79 .6 .953

Bono, G., McCullough, M. E., \& Root, L. M. (2008). Forgiveness, feeling connected to others, and well-being: Two longitudinal studies. Personality and Social Psychology Bulletin, 34(2), 182-195. https://doi.org/10.1177/0146167207310025

Bourgeois, P., \& Hess, U. (2008). The impact of social context on mimicry. Biological Psychology, 77, 343-352. https://doi.org/10.1016/j.biopsycho.2007.11.00

Bradbury, T. N. (2002). Invited program overview: Research on relationships as a prelude to action. Journal of Social and Personal Relationships, 19(5), 571-599. https://doi.org/10.1177/0265407502195001

Bugental, D. B. (2000). Acquisition of the algorithms of social life: A domain-based approach. Psychological Bulletin, 126(2), 187-219. https://doi.org/10.1037//0033-2909.126.2.187

Butler, E. A., Egloff, B., Wilhelm, F. H., Smith, N. C., Erickson, E. A., \& Gross, J. J. (2003). The social consequences of expressive suppression. Emotion, 3, 48-67. https://doi.org/10.1037/1528-3542.3.1.48 
RUNNING HEAD: INTIMATE RELATIONS

Butler, E. A., Lee, T. L., \& Gross, J. J. (2007). Emotion regulation and culture: Are the social consequences of emotion suppression culture-specific?. Emotion, 7(1), 30-48. https://doi.org/10.1037/1528-3542.7.1.30

Canevello, A., \& Crocker, J. (2010). Creating good relationships: Responsiveness, relationship quality, and interpersonal goals. Journal of Personality and Social Psychology, 99(1), 78. https://doi.org/10.1037/a0018186

Carson, J. W., Carson, K. M., Gil, K. M., \& Baucom, D. H. (2004). Mindfulness-based relationship enhancement. Behavior Therapy, 35, 471-494. https://doi.org/10.1016/S0005-7894(04)80028-5

Cavallo, J. V., Zee, K. S., \& Higgins, E. T. (2016). Giving the help that is needed: How regulatory mode impacts social support. Personality and Social Psychology Bulletin, 42(8), 1111-1128. https://doi.org/10.1177/0146167216651852

Chen, J. M., Kim, H. S., Sherman, D. K., \& Hashimoto, T. (2015). Cultural differences in support provision: The importance of relationship quality. Personality and Social Psychology Bulletin, 41(11), 1575-1589. https://doi.org/: 10.1177/0146167215602224

Christensen, A., \& Heavey, C. L. (1999). Interventions for couples. Annual Review of Psychology, 50, 165-190. https://doi.org/10.1037/0022-006X.68.2.351

Christophe, V., \& Rimé, B. (1997). Exposure to the social sharing of emotion: Emotional impact, listener responses and the secondary social sharing. European Journal of Social Psychology, 27, 37-54. https://doi.org/10.1002/(SICI)1099-0992(199701)27:1<37::AIDEJSP806>3.0.CO;2-1 
RUNNING HEAD: INTIMATE RELATIONS

Clark, M. S., Mills, J., \& Powell, M. C. (1986). Keeping track of needs in communal and exchange relationships. Journal of Personality and Social Psychology, 51(2), 333-338. https://doi.org/0022-3514/86/100.75

Clark, M. S., \& Monin, J. K. (2006). Giving and receiving communal responsiveness as love. In R. J. Sternberg \& K. Weis (Eds.), The new psychology of love (2nd ed., pp. 200-221). New Haven, CT: Yale University Press.

Coan, J. A., Schaefer, H. S., \& Davidson, R. J. (2006). Lending a hand: Social regulation of the neural response to threat. Psychological Science, 17, 1032-1039. https://doi.org/10.1111/j.1467-9280.2006.01832.x

Cohen, S. (2004). Social relationships and health. American Psychologist, 59(8), 676-684. https://doi.org/10.1037/0003-066x.59.8.676

Collins, N. L., \& Feeney, B. C. (2000). A safe haven: An attachment theory perspective on support seeking and caregiving in intimate relationships. Journal of Personality and Social Psychology, 78(6), 1053-1073. https://doi.org/10.1037//0022-3514.78.6.1053

Collins, N. L., \& Feeney, B. C. (2004). Working models of attachment shape perceptions of social support: Evidence from experimental and observational studies. Journal of Personality and Social Psychology, 87, 363-383. https://doi.org/10.1037/00223514.87.3.363

Collins, N. L., \& Miller, L. C. (1994). Self-disclosure and liking: A meta-analytic review. Psychological Bulletin, 116(3), 457-475. https://doi.org/10.1037/0033-2909.116.3.457

Cordova, J. V., Gee, C. B., \& Warren, L. Z. (2005). Emotional skillfulness in marriage: Intimacy as a mediator of the relationship between emotional skillfulness and marital satisfaction. 
RUNNING HEAD: INTIMATE RELATIONS

Journal of Social \& Clinical Psychology, 24(2), 218-235.

https://doi.org/10.1521/jscp.24.2.218.62270

Cordova, J. V., \& Scott, R. L. (2001) Intimacy: A behavioral interpretation. The Behavior Analyst, 24(1), 75-86. https://doi.org/10.1007/bf03392020

Coyne, J. C. (1976). Depression and the responses of others. Journal of Abnormal Psychology, 85, 186-193. https://doi.org/10.1037/0021-843X.85.2.186

Coyne, J. C., Wortman, C. B., \& Lehman, D. R. (1988). The other side of support: Emotional overinvolvement and miscarried helping. In B. H. Gottlieb, B. H. Gottlieb (Eds.), Marshaling social support: Formats, processes, and effects (pp. 305-330). Thousand Oaks, CA: Sage Publications, Inc.

Cramer, D., \& Jowett, S. (2010). Perceived empathy, accurate empathy and relationship satisfaction in heterosexual couples. Journal of Social and Personal Relationships, 27, 327-349. https://doi.org/10.1177\%2F0265407509348384

Curci, A., \& Rimé, B. (2012). The temporal evolution of social sharing of emotions and its consequences on emotional recovery: A longitudinal study. Emotion, 12(6), 1404-1414. https://doi.org/10.1037/a0028651

Cutrona, C. E. (1990). Stress and social support: In search of optimal matching. Journal of Social and Clinical Psychology, 9(1), 3-14. https://doi.org/10.1521/jscp.1990.9.1.3

Cutrona, C. E., Shaffer, P. A., Wesner, K. A., \& Gardner, K. A. (2007). Optimally matching support and perceived spousal sensitivity. Journal of Family Psychology, 21(4), 754-758. https://doi.org/10.1037/0893-3200.21.4.754

Dahl, J., Stewart, I., Martell, C. R., \& Kaplan, J. S. (2014). ACT and RFT in relationships: Helping clients deepen intimacy and maintain healthy commitments using acceptance 
RUNNING HEAD: INTIMATE RELATIONS

and commitment therapy and relational frame theory. Oakland, CA: New Harbinger Publications.

Darrow, S. M., \& Follette, W. C. (2014). Where's the beef?: Reply to Kanter, Holman, and Wilson. Journal of Contextual Behavioral Science, 3(4), 265-268. https://doi.org/10.1016/j.jcbs.2014.08.007

Darwin, C. (2005). The expression of emotion in man and animals. New York, NY: Appleton. https://doi.org/10.5962/bhl.title.4820

Davis, M. H., \& Oathout, H. A. (1987). Maintenance of satisfaction in romantic relationships: Empathy and relational competence. Journal of Personality and Social Psychology, 53(2), 397-410. https://doi.org/10.1037/0022-3514.53.2.397

Debrot, A., Cook, W. L., Perrez, M., \& Horn, A. B. (2012). Deeds matter: Daily enacted responsiveness and intimacy in couples' daily lives. Journal of Family Psychology, 26(4), 617-627. https://doi.org/10.1037/a0028666

Debrot, A., Schoebi, D., Perrez, M., \& Horn, A. B. (2013). Touch as an interpersonal emotion regulation process in couples' daily lives: The mediating role of psychological intimacy. Personality and Social Psychology Bulletin, 39(10), 1373-1385. https://doi.org/10.1177/0146167213497592

Debrot, A., Schoebi, D., Perrez, M., \& Horn, A. B. (2014). Stroking your beloved one's white bear: Responsive touch by the romantic partner buffers the negative effect of thought suppression on daily mood. Journal of Social and Clinical Psychology, 33(1), 75-97. https://doi.org/10.1521/jscp.2014.33.1.75

Deci, E., La Guardia, J. G., Moller, A. C., Scheiner, M. J., \& Ryan, R. M. (2006). On the benefits of giving as well as receiving autonomy support: Mutuality in close friendships. 
RUNNING HEAD: INTIMATE RELATIONS

Personality and Social Psychology Bulletin, 32, 313-327.

https://doi.org/10.1177/0146167205282148

Descutner, C. J., \& Thelen, M. H. (1991). Development and validation of a Fear-of-Intimacy Scale. Psychological assessment: A journal of consulting and clinical psychology, 3(2), 218-225. https://doi.org/10.1037/1040-3590.3.2.218

Dimberg, U., Thunberg, M., \& Elmehed, K. (2000) Unconscious facial reactions to emotional facial expressions. Psychological Science, 11, 86-89. https://doi.org/10.1111/14679280.00221

Doi, S. C., \& Thelen, M. H. (1993). The Fear-of-Intimacy Scale: Replication and extension. Psychological Assessment, 5(3), 377-383. https://doi.org/10.1037/1040-3590.5.3.377

Downey, G., \& Feldman, S. I. (1996). Implications of rejection sensitivity for intimate relationships. Journal of Personality and Social Psychology, 70(6), 1327-1343. https://doi.org/10.1037//0022-3514.70.6.1327

Duck, S., \& Perlman, D. (1985). The thousand islands of personal relationships: A prescriptive analysis for future explorations. In S. Duck \& D. Perlman (Eds.), Understanding personal relationships: An interdisciplinary approach (pp. 1-15). London: Sage.

Duckworth, M. P. (2009). Assertiveness skills and the management of related factors. In W. T. O'Donohue, J. E. Fisher, W. T. O'Donohue, J. E. Fisher (Eds.), General principles and empirically supported techniques of cognitive behavior therapy (pp. 124-132). Hoboken, NJ: John Wiley \& Sons Inc.

Dyregrov, K. (2003). Micro-sociological analysis of social support following traumatic bereavement: Unhelpful and avoidant responses from the community. Omega, 48, 23-44. https://doi.org/10.2190/T3NM-VFBK-68R0-UJ60 
RUNNING HEAD: INTIMATE RELATIONS

Eisenberg, N., Spinrad, T. L., \& Knafo-Noam, A. (2015). Prosocial development. Handbook of child psychology and developmental science, 1-47.

https://doi.org/10.1002/9781118963418.childpsy315

Emmons, R. A., \& Colby, P. M. (1995). Emotional conflict and well-being: Relation to perceived availability, daily utilization, and observer reports of social support. Journal of Personality and Social Psychology, 68(5), 947-959. https://doi.org/10.1037/00223514.68.5.947

Feeney, B. C., \& Collins, N. L. (2001). Predictors of caregiving in adult intimate relationships: An attachment theoretical perspective. Journal of Personality and Social Psychology, 80(6), 972-994. https://doi.org/10.1037//0022-3514.80.6.972

Feeney, B. C., \& Collins, N. L. (2003). Motivations for caregiving in adult intimate relationships: Influences on caregiving behavior and relationship functioning. Personality and Social Psychology Bulletin, 29(8), 950-968.

https://doi.org/10.1177/0146167203252807

Feeney, B. C., \& Collins, N. L. (2015). A new look at social support: A theoretical perspective on thriving through relationships. Personality and Social Psychology Review, 19(2), 113147. https://doi.org/10.1177/1088868314544222

Fitzsimons, G. M., \& Shah, J. Y. (2008). How goal instrumentality shapes relationship evaluations. Journal of Personality and Social Psychology, 95, 319-337. https://doi.org/10.1037/0022-3514.95.2.319

Floyd, K., Mikkelson, A. C., Tafoya, M. A., Farinelli, L., La Valley, A. G., Judd, J., ... \& Wilson, J. (2007). Human affection exchange: XIV. Relational affection predicts resting 
RUNNING HEAD: INTIMATE RELATIONS

heart rate and free cortisol secretion during acute stress. Behavioral Medicine, 32(4), 151156. https://doi.org/10.3200/BMED.32.4.151-156

Floyd, K., \& Riforgiate, S. (2008). Affectionate communication received from spouses predicts stress hormone levels in healthy adults. Communication Monographs, 75(4), 351-368. https://doi.org/10.1080/03637750802512371

Forest, A. L., Kille, D. R., Wood, J. V., \& Holmes, J. G. (2014). Discount and disengage: How chronic negative expressivity undermines partner responsiveness to negative disclosures. Journal of Personality and Social Psychology, 107(6), 1013-1032. https://doi.org/10.1037/a0038163

Forest, A. L., \& Wood, J. V. (2011). When partner caring leads to sharing: Partner responsiveness increases expressivity, but only for individuals with low self-esteem. Journal of Experimental Social Psychology, 47, 843-848. https://doi.org/10.1016/j.jesp.2011.03.005

Fredrickson, B. L., Cohn, M. A., Coffey, K. A., Pek, J., \& Finkel, S. M. (2008). Open hearts build lives: Positive emotions, induced through loving-kindness meditation, build consequential personal resources. Journal of Personality and Social Psychology, 95(5), 1045-1062. https://doi.org/10.1037/a0013262

Gable, S. L., Gonzaga, G. C., \& Strachman, A. (2006). Will you be there for me when things go right? Supportive responses to positive event disclosures. Journal of Personality and Social Psychology, 91(5), 904-917. https://doi.org/10.1037/0022-3514.91.5.904

Gable, S. L., Gosnell, C. L., Maisel, N. C., \& Strachman, A. (2012). Safely testing the alarm: Close others' responses to personal positive events. Journal of Personality and Social Psychology, 103, 963-982. https://doi.org/10.1037/a0029488 
RUNNING HEAD: INTIMATE RELATIONS

Gable, S. L., Reis, H. T., Impett, E. A., \& Asher, E. R. (2004). What do you do when things go right? The intrapersonal and interpersonal benefits of sharing positive events. Journal of Personality and Social Psychology, 87(2), 228-245. https://doi.org/10.1037/00223514.87.2.228

Gerhart, J. I., Baker, C. N., Hoerger, M., \& Ronan, G. F. (2014). Experiential avoidance and interpersonal problems: A moderated mediation model. Journal of Contextual Behavioral Science, 3(4), 291-298. https://doi.org/10.1016/j.jcbs.2014.08.003

Gibson, K. R., Harari, D., \& Marr, J. C. (2018). When sharing hurts: How and why selfdisclosing weakness undermines the task-oriented relationships of higher status disclosers. Organizational Behavior and Human Decision Processes, 144, 25-43. https://doi.org/10.1016/j.obhdp.2017.09.001

Girme, Y. U., Overall, N. C., \& Simpson, J. A. (2013). When visibility matters: Short-term versus long-term costs and benefits of visible and invisible support. Personality and Social Psychology Bulletin, 39(11), 1441-1454.

https://doi.org/10.1177/0146167213497802

Gleason, M. E. J., Iada, M., Bolger, N., \& Shrout, P. E. (2003). Daily supportive equity in close relationships. Personality and Social Psychology Bulletin, 29, 1036-1045. https://doi.org/10.1177/0146167203253473

Gleason, M. E. J., Iida, M., Shrout, P. E., \& Bolger, N. (2008). Receiving support as a mixed blessing: Evidence for dual effects of support on psychological outcomes. Journal of Personality and Social Psychology, 94, 824-838. https://doi.org/10.1037/00223514.94.5.824 
RUNNING HEAD: INTIMATE RELATIONS

Golan, O., \& Baron-Cohen, S. (2006). Systemizing empathy: Teaching adults with Asperger syndrome or high-functioning autism to recognize complex emotions using interactive multimedia. Development and Psychopathology, 18, 591-617. https://doi.org/10.1017/S0954579406060305

Gordon, A. M., Impett, E. A., Kogan, A., Oveis, C., \& Keltner, D. (2012). To have and to hold: Gratitude promotes relationship maintenance in intimate bonds. Journal of Personality and Social Psychology, 103(2), 257-274. https://doi.org/10.1037/a0028723

Gordon, S., \& Waldo, M. (1984). The effects of assertiveness training on couples' relationships. American Journal of Family Therapy, 12(1), 73-77. https://doi.org/10.1080/01926188408250160

Gosnell, C. L., \& Gable, S. L. (2013). Attachment and capitalizing on positive events. Attachment \& Human Development, 15(3), 281-302. https://doi.org/10.1080/14616734.2013.782655

Graham, S. M., Huang, J. Y., Clark, M. S., \& Helgeson, V. S. (2008). The positives of negative emotions: Willingness to express negative emotions promotes relationships. Personality and Social Psychology Bulletin, 34(3), 394-406. https://doi.org/10.1177/0146167207311281

Grant, A. M., \& Gino, F. (2010). A little thanks goes a long way: Explaining why gratitude expressions motivate prosocial behavior. Journal of Personality and Social Psychology, 98(6), 946-55. https://doi.org/10.1037/a0017935

Gross, J. J., \& John, O. P. (2003). Individual differences in two emotion regulation processes: Implications for affect, relationships, and wellbeing. Journal of Personality and Social Psychology, 85, 348-362. http:/doi.org/10.1037/0022-3514.85.2.348 
RUNNING HEAD: INTIMATE RELATIONS

Harris, R. (2009). ACT with love: Stop struggling, reconcile differences, and strengthen your relationship with acceptance and commitment therapy. Oakland, CA: New Harbinger Publications.

Harrison, M. A., \& Shortall, J. C. (2011). Women and men in love: Who really feels it and says it first? The Journal of Social Psychology, 151(6), 727-736. https://doi.org/10.1080/00224545.2010.522626

Hasson, U., Ghazanfar, A. A., Galantucci, B., Garrod, S., \& Keysers, C. (2012). Brain to brain coupling: A mechanism for creating and sharing a social world. Trends in Cognitive Sciences, 16, 114-121. https://doi.org/10.1016/j.tics.2011.12.007

Haworth, K., Kanter, J. W., Tsai, M., Kuczynski, A. M., Rae, J. R., \& Kohlenberg, R. J. (2015). Reinforcement matters: A preliminary, laboratory-based component-process analysis of Functional Analytic Psychotherapy's model of social connection. Journal of Contextual Behavioral Science, 4(4), 281-291. https://doi.org/10.1016/j.jcbs.2015.08.003

Hayes, S. C., Barnes-Holmes, D., \& Wilson, K. G. (2012). Contextual Behavioral Science: Creating a science more adequate to the challenge of the human condition. Journal of Contextual Behavioral Science, 1(1-2), 1-16. https://doi.org/10.1016/j.jcbs.2012.09.004

Hayes, S. C., Follette, V. M., \& Linehan, M. M. (Eds.) (2004). Mindfulness and acceptance: Expanding the cognitive-behavioral tradition. New York, NY: Guilford Press.

Hayes, S. C., Strosahl, K., Wilson, K. G., Bissett, R. T., Pistorello, J., Toarmino, D., ... , \& McCurry, S. M. (2004). Measuring experiential avoidance: A preliminary test of a working model. The Psychological Record, 54 (4): 553-78. https://doi.org/10.1007/BF03395492. 
Hayes, S. C., Wilson, K. W., Gifford, E. V., Follette, V. M., \& Strosahl, K. (1996). Experiential avoidance and behavioral disorders: A functional dimensional approach to diagnosis and treatment. Journal of Consulting and Clinical Psychology, 64(6), 1152-1168.

Heerey, E. A., \& Kring, A. M. (2007). Interpersonal consequences of social anxiety. Journal of Abnormal Psychology, 116, 125-134. https://doi.org/10.1037/0021-843X.116.1.125

Helgeson, V. S. (1993). Two important distinctions in social support: Kind of support and perceived versus received. Journal of Applied Social Psychology, 23, 825-845. https://doi.org/10.1111/j.1559-1816.1993.tb01008.x

Heppner, W. L., Kernis, M. H., Lakey, C. E., Campbell, W. K., Goldman, B. M., Davis, P. J., \& Cascio, E. V. (2008). Mindfulness as a means of reducing aggressive behavior: Dispositional and situational evidence. Aggressive Behavior, 34(5), 486-496. https://doi.org/10.1002/ab.20258

Hodgins, H. S., \& Liebeskind, E. (2003). Apology versus defense: Antecedents and consequences. Journal of Experimental Social Psychology, 39, 297-316. https://doi.org/10.1016/S0022-1031(03)00024-6

Holt-Lunstad, J., \& Smith, T. B. (2012). Social relationships and mortality. Social and Personality Psychology Compass, 6(1), 41-53. https://doi.org/10.1111/j.17519004.2011.00406.x

Holt-Lunstad, J., Smith, T. B., \& Layton, B. (2010). Social relationships and mortality: A metaanalysis. PLoS Medicine, 7(7), e1000316. https://doi.org/10.1371/journal.pmed.1000316 Hölzel, B. K., Lazar, S. W., Gard, T., Schuman-Oliver, Z., Vago, D. R., \& Ott, U. (2011). How does mindfulness meditation work? Proposing mechanisms of action from a conceptual 
RUNNING HEAD: INTIMATE RELATIONS

and neural perspective. Perspectives on Psychological Science, 6, 537-559. https://doi.org/10.1177/1745691611419671

Horowitz, L. M., Krasnoperova, E. N., Tatar, D. G., Hansen, M. B., Person, E. A., Galvin, K. L., \& Nelson, K. L. (2001). The way to console may depend on the goal: Experimental studies of social support. Journal of Experimental Social Psychology, 37(1), 49-61. https://doi.org/10.1006/jesp.2000.1435

House, J. S., Landis, K. R., \& Umberson, D. (1988). Social relationships and health. Science, 241(4865), 540-545. https://doi.org/10.1126/science.3399889

Ickes, W. (1997). Empathic accuracy. New York, NY: Guilford Press. https://doi.org/10.1017/CBO9780511543753.023

Ingram, K. M., Betz, N. E., Mindes, E. J., Schmitt, M. M., \& Smith, N. G. (2001). Unsupportive responses from others concerning a stressful life event: Development of the Unsupportive Social Interactions Inventory. Journal of Social and Clinical Psychology, 20(2), 173-207. https://doi.org/10.1521/jscp.20.2.173.22265

Jazaieri, H., McGonigal, K., Jinpa, T., Doty, J. R., Gross, J. J., \& Goldin, P. R. (2014). A randomized controlled trial of compassion cultivation training: Effects on mindfulness, affect, and emotion regulation. Motivation and Emotion, 38(1), 23-35. https://doi.org/10.1007/s11031-013-9368-z

Jiang, J., Dai, B., Peng, D., Liu, L., \& Lu, C. (2012). Neural synchronization during face-to-face communication. The Journal of Neuroscience, 32(45), 16064-16069. https://doi.org/0.1523/JNEUROSCI.2926-12.2012 
RUNNING HEAD: INTIMATE RELATIONS

Joiner, T. E., Jr., \& Metalsky, G. I. (2001). Excessive reassurance seeking: Delineating a risk factor involved in the development of depressive symptoms. Psychological Science, 12, 371-378. https://doi.org/10.1111/1467-9280.00369

Kabat-Zinn, J. (2009). Wherever you go, there you are: Mindfulness meditation in everyday life. New York, NY: Hachette Books.

Kanter, J. W., Corey, M. D., Manbeck, K. E., \& Rosen, D. C. (2019). Contextual-behavioral science interventions to address racism. In M. E. Levin, J. Kraft, \& M. Twohig (Eds.), Recent Innovations in ACT. Oakland, CA: New Harbinger Books.

Kanter, J. W., Holman, G., \& Wilson, K. G. (2014). Where is the love? Contextual behavioral science and behavior analysis. Journal of Contextual Behavioral Science, 3(2), 69-73. https://doi.org/10.1016/j.jcbs.2014.02.001

Kanter, J. W., Kuczynski, A. M., Tsai, M., \& Kohlenberg, R. (2018). A brief contextual behavioral intervention to improve relationships: A randomized trial. Journal of Contextual Behavioral Science, 10, 75-84. https://doi.org/10.1016/j.jcbs.2018.09.001

Kanter, J. W., Tsai, M., Holman, G., \& Koerner, K. (2013). Preliminary data from a randomized pilot study of web-based Functional Analytic Psychotherapy therapist training. Psychotherapy: Research, Theory, Practice, Training, 50, 248-255. https://doi.org/10.1037/a0029814

Kappes, H. B., \& Shrout, P. E. (2011). When goal sharing produces support that is not caring. Personality and Social Psychology Bulletin, 37(5), 662-673. https://doi.org/10.1177/0146167211399926

Kashdan, T. B., Ferssizidis, P., Farmer, A. S., Adams, L. M., \& McKnight, P. E. (2013). Failure to capitalize on sharing good news with romantic partners: Exploring positivity deficits of 
RUNNING HEAD: INTIMATE RELATIONS

socially anxious people with self-reports, partner reports, and behavioral observations. Behaviour Research and Therapy, 51(10), 656-668.

https://doi.org/10.1016/j.brat.2013.04.006

Kashdan, T. B., Volkmann, J. R., Breen, W. E., \& Han, S. (2007). Social anxiety and romantic relationships: The costs and benefits of negative emotion expression are contextdependent. Journal of Anxiety Disorders, 21, 475-492.

https://doi.org/10.1016/j.janxdis.2006.08.007

Keng, S. L., Smoski, M. J., \& Robins, C. J. (2011). Effects of mindfulness on psychological health: A review of empirical studies. Clinical Psychology Review, 31, 1041-1056. https://doi.org/10.1016/j.cpr.2011.04.006

Kennedy-Moore, E., \& Watson, J. C. (2001). How and when does emotional expression help? Review of General Psychology, 5(3), 187-212. https://doi.org/10.1037/1089-2680.5.3.187

Knee, C. R., Lonsbary, C., Canevello, A., \& Patrick, H. (2005). Self-determination and conflict in romantic relationships. Journal of Personality and Social Psychology, 89, 997-1009. https://doi.org/10.1037/0022-3514.89.6.997

Knudsen, E. I. (2004). Sensitive periods in the development of the brain and behavior. Journal of cognitive neuroscience, 16(8), 1412-1425. https://doi.org/10.1162/0898929042304796

Koestner, R., Powers, T. A., Carbonneau, N., Milyavskaya, M., \& Chua, S. N. (2012). Distinguishing autonomous and directive forms of goal support: Their effects on goal progress, relationship quality, and subjective well-being. Personality and Social Psychology Bulletin, 38, 1609-1620. https://doi.org/10.1177/0146167212457075

Kohlenberg, R. J., Tsai, M., Kuczynski, A. M., Rae, J. R., Lagbas, E., Lo, J., \& Kanter, J. W. (2015). A brief, interpersonally oriented mindfulness intervention incorporating 
RUNNING HEAD: INTIMATE RELATIONS

Functional Analytic Psychotherapy' s model of awareness, courage and love. Journal of contextual Behavioral Science, 4(2), 107-111.

Kuczynski, A. M., Kanter, J. W., Wetterneck, C. T., Olaz, F. O., Singh, R. S., Lee, E. B., ..., \& Corey, M. D. (in press). Measuring intimacy as a contextual behavioral process: Psychometric development and evaluation of the Awareness, Courage, and Responsiveness Scale. Journal of Contextual Behavioral Science. https://doi.org/10.1016/j.jcbs.2019.02.004

Lakey, B., McCabe, K. M., Fisicaro, S. A., \& Drew, J. B. (1996). Environmental and personal determinants of support perceptions: Three generalizability studies. Journal of Personality and Social Psychology, 70(6), 1270-1280. https://doi.org/10.1037//00223514.70.6.1270

Langston, C. A. (1994). Capitalizing on and coping with daily life events: Expressive responses to positive events. Journal of Personality and Social Psychology, 67, 1112-1125. https://doi.org/10.1037/0022-3514.67.6.1112

Laurenceau, J., Barrett, L. F., \& Pietromonaco, P. R. (1998). Intimacy as an interpersonal process: The importance of self-disclosure, partner disclosure, and perceived partner responsiveness in interpersonal exchanges. Journal of Personality and Social Psychology, 74(5), 1238-1251. https://doi.org/10.1037/0022-3514.74.5.1238

Lawrence, E., \& Bradbury, T. N. (2007). Trajectories of change in physical aggression and marital satisfaction. Journal of Family Psychology, 21, 236-247. https://doi.org/10.1037/0893-3200.21.2.236

Leary, M. R., \& Carrie, A. (2001). Hurt feelings: The neglected emotion. In R. M. Kowalski (Ed.), Behaving badly: Aversive behaviors in interpersonal relationships (pp. 151-175). 
RUNNING HEAD: INTIMATE RELATIONS

Washington, DC: American Psychological Association. https://doi.org/10.1037/10365006

Lehman, D. R., Ellard, J. H., \& Wortman, C. B. (1986). Social support for the bereaved: Recipients' and providers' perspectives on what is helpful. Journal of Consulting and Clinical Psychology, 54(4), 438-446. https://doi.org/10.1037/0022-006X.54.4.438

Lemay, E. P., \& Clark, M. S. (2008). "Walking on eggshells": How expressing relationship insecurities perpetuates them. Journal of Personality and Social Psychology, 95(2), 420441. https://doi.org/10.1037/0022-3514.95.2.420

Levin, M. E., Hildebrandt, M. J., Lillis, J., \& Hayes, S. C. (2012). The impact of treatment components suggested by the psychological flexibility model: A meta-analysis of laboratory-based component studies. Behavior Therapy, 443, 741-756. https://doi.org/10.1016/j.beth.2012.05.003.

Lewis, K. L., Hodges, S. D., Laurent, S. M., Srivastava, S., \& Biancarosa, G. (2012). Reading between the minds: The use of stereotypes in empathic accuracy. Psychological Science, 23, 1040-1046. https://doi.org/10.1177/0956797612439719

Linehan, M. (1993). Cognitive-behavioral treatment of borderline personality disorder. Guilford Press: New York, NY.

Linehan, M. (2014). DBT skills training manual, second edition. New York, NY: Guilford Press. https://doi.org/10.1097/NMD.0000000000000387

Logan, J. M., \& Cobb, R. J. (2013). Trajectories of relationship satisfaction: Independent contributions of capitalization and support perceptions. Personal Relationships, 20(2), 277-293. https://doi.org/10.1111/j.1475-6811.2012.01408.x 
RUNNING HEAD: INTIMATE RELATIONS

Long, E. C., \& Andrews, D. W. (1990). Perspective taking as a predictor of marital adjustment. Journal of Personality and Social Psychology, 59(1), 126-131. https://doi.org/10.1037/0022-3514.59.1.126

Maisel, N. C., \& Gable, S. L. (2009). The paradox of received social support: The importance of responsiveness. Psychological Science, 20(8), 928-932. https://doi.org/10.1111/j.14679280.2009.02388.x

Maisel, N. C., Gable, S. L., \& Strachman, A. (2008). Responsive behaviors in good times and in bad. Personal Relationships, 15(3), 317-338. https://doi.org/10.1111/j.14756811.2008.00201.x

Maitland, D. W. M., Kanter, J. W., Manbeck, K. M., \& Kuczynski, A. M. (2017). Relationshipscience informed clinically relevant behaviors in Functional Analytic Psychotherapy: The awareness, courage, and love model. Journal of Contextual Behavioral Science, 6(4), 347-359. https://doi.org/10.1016/j.jcbs.2017.07.002

Manbeck, K. E., Kanter, J. W., Kuczynski, A. M., Fine, L., Corey, M. D., \& Maitland, D. W. M. (2018). Improving relations among conservatives and liberals on a college campus: A preliminary trial of a contextual-behavioral intervention. Journal of Contextual Behavioral Science, 10, 120-125. http://dx.doi.org/10.1016/j.jcbs.2018.10.006

Manbeck, K. E., Kanter, J. W., Kuczynski, A. M., Maitland, D. W. M., \& Corey, M. D. (in press). Fear-of-intimacy in the Interpersonal Process Model: An investigation in two parts. Journal of Social and Personal Relationships.

Manne, S., Ostroff, J., Rini, C., Fox, K., Goldstein, L., \& Grana, G. (2004). The interpersonal process model of intimacy: The role of self-disclosure, partner disclosure, and partner 
RUNNING HEAD: INTIMATE RELATIONS

responsiveness in interactions between breast cancer patients and their partners. Journal of Family Psychology, 18(4), 589-599. https://doi.org/10.1037/0893-3200.18.4.589

Marcus, D. K., \& Nardone, M. E. (1992). Depression and interpersonal rejection. Clinical Psychology Review, 12, 433-449. https://doi.org/10.1016/0272-7358(92)90126-S

Marigold, D. C., Cavallo, J. V., Holmes, J. G., \& Wood, J. V. (2014). You can't always give what you want: The challenge of providing social support to low self-esteem individuals. Journal of Personality and Social Psychology, 107, 56-80.

https://doi.org/10.1037/a0036554

Marshall, T. C. (2008). Cultural differences in intimacy: The influence of gender-role ideology and individualism - collectivism. Journal of Social and Personal Relationships, 25(1), 143-168. https://doi.org/10.1177/0265407507086810

McClure, M. J., Xu, J. H., Craw, J. P., Lane, S. P., Bolger, N., \& Shrout, P. E. (2014). Understanding the costs of support transactions in daily life. Journal of Personality, 82(6), 563-574. https://doi.org/10.1111/jopy.12061

Mendlowicz, M. V., \& Stein, M. B. (2000). Quality of life in individuals with anxiety disorders. American Journal of Psychiatry, 157(5), 669-682. https://doi.org/10.1176/appi.ajp.157.5.669

Mikulincer, M., Shaver, P. R., Bar-On, N., \& Ein-Dor, T. (2010). The pushes and pulls of close relationships: Attachment insecurities and relational ambivalence. Journal of Personality and Social Psychology, 98(3), 450-468. https://doi.org/10.1037/a0017366

Molden, D. C., Lucas, G. M., Finkel, E. J., Kumashiro, M., \& Rusbult, C. E. (2009). Perceived support for promotion-focused and prevention-focused goals: Effects on well-being in 
RUNNING HEAD: INTIMATE RELATIONS

unmarried and married couples. Psychological Science, 20, 787-793.

https://doi.org/10.1111/j.1467-9280.2009.02362.x

Morelli, S. A., Lee, I. A., Arnn, M. E., \& Zaki, J. (2015). Emotional and instrumental support provision interact to predict well-being. Emotion, 15(4), 484-493. https://doi.org/10.1037/emo0000084

Morelli, S. A., Torre, J. B., \& Eisenberger, N. I. (2014). The neural bases of feeling understood and not understood. Social Cognitive and Affective Neuroscience, 9, 1890-1896. https://doi.org/10.1093/scan/nst191

Morton, T. L. (1978). Intimacy and reciprocity of exchange: A comparison of spouses and strangers. Journal of Personality and Social Psychology, 26(1), 72-81. https://doi.org/10.1037/0022-3514.36.1.72

Murray, S. L., Holmes, J. G., \& Collins, N. L. (2006). Optimizing assurance: The risk regulation system in relationships. Psychological Bulletin, 132, 641-666. https://doi.org/10.1037/0033-2909.132.5.641

Murray, S. L., Holmes, J. G., \& Griffin, D. W. (2000). Self-esteem and the quest for felt security: How perceived regard regulates attachment processes. Journal of Personality and Social Psychology, 78(3), 478-498. https://doi.org/10.1037/0022-3514.78.3.478

Nadler, A. (2015). The other side of helping: Seeking and receiving help. In D. A. Schroeder, W. G. Graziano, D. A. Schroeder, W. G. Graziano (Eds.), The Oxford handbook of prosocial behavior (pp. 307-328). New York, NY: Oxford University Press. https://doi.org/10.1093/oxfordhb/9780195399813.001.0001 
RUNNING HEAD: INTIMATE RELATIONS

Najdowski, A. C., Bergstrom, R., Tarbox, J., \& Clair, M. S. (2017). Teaching children with autism to respond to disguised mands. Journal of Applied Behavior Analysis, 50(4), 733743. https://doi.org/10.1002/jaba.413

Neff, L. A., \& Karney, B. R. (2005). To know you is to love you: The implications of global adoration and specific accuracy for marital relationships. Journal of Personality and Social Psychology, 88, 480-497. https://doi.org/10.1037/0022-3514.88.3.480

Niedenthal, P. M. (2007). Embodying emotion. Science, 316, 1002-1005. https://doi.org/10.1126/science.1136930

Nils, F., \& Rimé, B. (2012). Beyond the myth of venting: Social sharing modes determine the benefits of emotional disclosure. European Journal of Social Psychology, 42(6), 672-681. https://doi.org/10.1002/ejsp.1880

North, R. J., \& Swann, W. J. (2009). Self-verification $360^{\circ}$ : Illuminating the light and dark sides. Self and Identity, 8(2-3), 131-146. https://doi.org/10.1080/15298860802501516

Open Science Foundation. (2015). Estimating the reproducibility of psychological science. Science, 349(6251), aac4716-aac4716. https://doi.org/10.1126/science.aac4716

Overall, N. C., Fletcher, G. O., Simpson, J. A., \& Fillo, J. (2015). Attachment insecurity, biased perceptions of romantic partners' negative emotions, and hostile relationship behavior. Journal of Personality and Social Psychology, 108(5), 730-749. https://doi.org/10.1037/a0038987

Owen, W. F. (1987). The verbal expression of love by women and men as a critical communication event in personal relationships. Women's Studies In Communication, 10(1), 15-24. https://doi.org/10.1080/07491409.1987.11089701 
RUNNING HEAD: INTIMATE RELATIONS

Parkinson, B. (1996). Emotions are social. British Journal of Psychology, 87, 663-683. https://doi.org/10.1111/j.2044-8295.1996.tb02615.x

Patrick, H., Knee, C. R., Canevello, A., \& Lonsbary, C. (2007). The role of need fulfillment in relationship functioning and well-being: A self-determination theory perspective. Journal of Personality and Social Psychology, 92, 434-457. https://doi.org/10.1037/00223514.92.3.434

Pettit, J., \& Joiner, T. E. (2001) Negative-feedback seeking leads to depressive symptom increases under conditions of stress. Journal of Psychopathology and Behavioral Assessment, 23(1), 69-74. https://doi.org//10.1023/A:1011047708787

Porges, S. W. (2011). The polyvagal theory: Neurophysiological foundations of emotions, attachment, communication, self-regulation. New York: Norton \& Company.

Rademacher, L., Schulte-Rüther, M., Hanewald, B., \& Lammertz, S. (2015). Reward: From basic reinforcers to anticipation of social cues. In Wöhr M., Krach S. (Eds.), Social behavior from rodents to humans. Current topics in behavioral neurosciences (Vol 30, pp. 207221). Basel, Switzerland: Springer. https://doi.org/10.1007/7854_2015_429.

Reis, H. T. (2007). Steps toward the ripening of relationship science. Personal Relationships, 14(1), 1-23. https://10.1111/j.1475-6811.2006.00139.x

Reis, H. T., Clark, M. S., \& Holmes, J. G. (2004). Perceived partner responsiveness as an organizing construct in the study of intimacy and closeness. In D. J. Mashek \& A. Aron (Eds.), Handbook of closeness and intimacy (pp. 201-225). Mahwah, NJ: Lawrence Erlbaum. https://doi.org/10.1177/1948550610391914

Reis, H. T., \& Gable, S. L. (2015). Responsiveness. Current Opinion in Psychology, 1, 67-71. https://doi.org/10.1016/j.copsyc.2015.01.001 
RUNNING HEAD: INTIMATE RELATIONS

Reis, H. T., O'Keefe, S. D., \& Lane, R. D. (2017). Fun is more fun when others are involved. Journal of Positive Psychology, 12(6):547-557. https://doi.org/10.1080/17439760.2016.1221123

Reis, H. T., \& Patrick, B. C. (1996). Attachment and intimacy: Component processes. In E. T. Higgins \& A. W. Kruglanski (Eds.), Social psychology: Handbook of basic principles (pp. 523-563). New York, NY: Guilford Press.

Reis, H. T., \& Shaver, P. (1988). Intimacy as an interpersonal process. In S. Duck (Ed.), Handbook of personal relationships: Theory, research and interventions (pp. 367-389). Chichester, UK: Wiley.

Reis, H. T., Sheldon, K. M., Gable, S. L., Roscoe, J., \& Ryan, R. M. (2000). Daily well-being: The role of autonomy, competence, and relatedness. Personality and Social Psychology Bulletin, 26(4), 419-435. https://doi.org/10.1177/0146167200266002

Reyes Ortega, M. A., Kuczynski, A. M., Kanter, J. W., de Montis, I. A., \& Santos, M. M. (2019). A preliminary test of a social connectedness burnout intervention for Mexican mental health professionals. The Psychological Record.

Rimé, B. (2009). Emotion elicits the social sharing of emotion: Theory and empirical review. Emotion review, 1(1), 60-85. https://doi.org/10.1177/1754073908097189

Robinson, K. J., Hoplock, L. B., \& Cameron, J. J. (2015). When in doubt, reach out: Touch is a covert but effective mode of soliciting and providing social support. Social Psychological and Personality Science, 6(7), 831-839. https://doi.org/10.1177/1948550615584197

Rogers, C. R. (1951). Client-centered therapy. Washington, DC: American Psychological Association. 
RUNNING HEAD: INTIMATE RELATIONS

Rusbult, C. E., \& Van Lange, P. A. M. (1996). Interdependence processes. In E. T. Higgins \& A. Kruglanski (Eds.), Social psychology: Handbook of basic mechanisms and processes, (pp. 564-596). New York, NY: Guilford.

Rusbult, C. E., Verette, J., Whitney, G. A., Slovik, L. F., \& Lipkus, I. (1991). Accommodation processes in close relationships: Theory and preliminary empirical evidence. Journal of Personality and Social Psychology, 60, 53-78. https://doi.org/10.1037/0022-3514.60.1.53

Ryan, R. M., \& Deci, E. L. (2000). Self-determination theory and the facilitation of intrinsic motivation, social development, and well-being. American Psychologist, 55(1), 68-78. https://doi.org/10.1037/0003-066X.55.1.68

Ryff, C. D., \& Singer, B. (2000). Interpersonal flourishing: A positive health agenda for the new millennium. Personality and Social Psychology Review, 4(1), 30-44. https://doi.org/10.1207/s15327957pspr0401_4

Saxena, P., \& Mehrotra, S. (2010). Emotional disclosure in day-to-day living and subjective well being. Psychological Studies, 55(3), 208-218. https://doi.org/10.1007/s12646-010-0034-1

Schachner, D. A., Shaver, P. R., \& Mikulincer, M. (2005). Patterns of nonverbal behavior and sensitivity in the context of attachment relations. Journal of Nonverbal Behavior, 29, 141-169. https://doi.org/10.1007/s10919-005-4847-x

Schröder-Abé, M., \& Schütz, A. (2011). Walking in each other's shoes: Perspective taking mediates effects of emotional intelligence on relationship quality. European Journal of Personality, 25(2), 155-169. https://doi.org/10.1002/per.818

Segrin, C., \& Abramson, L. Y. (1994). Negative reactions to depressive behaviors: A communication theories analysis. Journal of Abnormal Psychology, 103, 655-668. https://doi.org/10.1037/0021-843X.103.4.655 
RUNNING HEAD: INTIMATE RELATIONS

Shimanoff, S. B. (1988). Degree of emotional expressiveness as a function of face-needs, gender, and interpersonal relationship. Communication Reports, 1, 43-59. https://doi.org/10.1080/08934218809367464

Shrout, P. E., Herman, C. M., \& Bolger, N. (2006). The costs and benefits of practical and emotional support on adjustment: A daily diary study of couples experiencing acute stress. Personal Relationships, 13(1), 115-134. https://doi.org/10.1111/j.14756811.2006.00108.x

Simpson, J. A. (2007). Foundations of interpersonal trust. In A. W. Kruglanski \& E. T. Higgins, (Eds.), Social psychology: Handbook of basic principles (2nd ed., pp. 587-607). New York, NY: Guilford Press.

Simpson, J. A., Rholes, W. S., \& Phillips, D. (1996). Conflict in close relationships: An attachment perspective. Journal of Personality and Social Psychology, 71, 899-914. https://doi.org/10.1037/0022-3514.71.5.899

Skinner, B. F. (1957). Verbal behavior. Englewood Cliffs, NJ: Prentice Hall.

Sprecher, S., \& Treger, S. (2015). The benefits of turn-taking reciprocal self-disclosure in getacquainted interactions. Personal Relationships, 22(3), 460-475. https://doi.org/10.1111/pere.12090

Sprecher, S., Treger, S., Wondra, J. D., Hilaire, N., \& Wallpe, K. (2013). Taking turns: Reciprocal self-disclosure promotes liking in initial interactions. Journal of Experimental Social Psychology, 49(5), 860-866. https://doi.org/10.1016/j.jesp.2013.03.017

Srivastava, S., Tamir, M., McGonigal, K. M., John, O. P., \& Gross, J. J. (2009). The social costs of emotional suppression: A prospective study of the transition to college. Journal of Personality and Social Psychology, 96, 883-897. https://doi.org/10.1037/a0014755 
RUNNING HEAD: INTIMATE RELATIONS

Suhr, J., Cutrona, C., Krebs, K., \& Jensen, S. (2004). The social support behavior code. In P. K. Kerig \& D. Baucom (Eds.), Couple observational coding systems (pp. 311-318). Mahwah, NJ: Erlbaum.

Sullivan, K. T., Pasch, L. A., Lawrence, E., \& Bradbury, T. N. (2015). Physical aggression, compromised social support, and 10-year marital outcomes: Testing a relational spillover model. Journal of Family Psychology, 29(6), 931-937. https://doi.org/10.1037/fam0000125

Sundberg, M. L., \& Michael, J. (2001). The benefits of Skinner's analysis of verbal behavior for children with autism. Behavior Modification, 25(5), 698-724. https://doi.org/10.1177/0145445501255003

Swann, W. B., Jr. (1990). To be adored or to be known: The interplay of self-enhancement and self-verification. R. M. Sorrentino \& E. T. Higgins (Eds.), Handbook of motivation and cognition (Vol. 2, pp. 408-480). New York, NY: Guilford.

Tsai, M., Callaghan, G. M., \& Kohlenberg, R. J. (2013). The use of awareness, courage, therapeutic love, and behavioral interpretation in functional analytic psychotherapy. Psychotherapy, 50(3), 366-370. https://doi.org/10.1037/a0031942

Tsai, M., Kohlenberg, R. J., Kanter, J. W., Kohlenberg, B., Follette, W. C., \& Callaghan, G. M. (2009). A guide to functional analytic psychotherapy. Awareness, courage, love and behaviorism. New York, NY: Springer.

Van Kleef, G. A. (2010). The emerging view of emotion as social information. Social and Personality Psychology Compass, 4(5), 331-343. https://doi.org/10.1111/j.17519004.2010.00262.x 
RUNNING HEAD: INTIMATE RELATIONS

Verhofstadt, L. L., Buysse, A., Ickes, W., Davis, M., \& Devoldre, I. (2008). Support provision in marriage: The role of emotional similarity and empathic accuracy. Emotion, 8, 792-802. https://doi.org/10.1037/a0013976

Vicaria, I. M., \& Dickens, L. (2016). Meta-analyses of the intra- and interpersonal outcomes of interpersonal coordination. Journal of Nonverbal Behavior, 40(4), 335-361. https://doi.org/10.1007/s10919-016-0238-8

Vilardaga, R., Hayes, S. C., Levin, M. E., \& Muto, T. (2009). Creating a strategy for progress: A contextual behavioral science approach. The Behavior Analyst, 32(1), 105-133. https://doi.org/10.1007/bf03392178

Vinokur, A., Schul, Y., \& Caplan, R. D. (1987). Determinants of perceived social support: Interpersonal transactions, personal outlook, and transient affective states. Journal of Personality and Social Psychology, 53(6), 1137-1145. https://doi.org/10.1037//00223514.53.6.1137

Wachs, K., \& Cordova, J. V. (2007). Mindful relating: Exploring mindfulness and emotion repertoires in intimate relationships. Journal of Marital and Family Therapy, 33(4), 464481. https://doi.org/10.1111/j.1752-0606.2007.00032.x

Wagner, U., Galli, L., Schott, B. H., Wold, A., van der Schalk, J., Manstead, A. R., \& ... Walter, H. (2015). Beautiful friendship: Social sharing of emotions improves subjective feelings and activates the neural reward circuitry. Social Cognitive and Affective Neuroscience, 10(6), 801-808. https://doi.org/10.1093/scan/nsu121

Watson, D., \& Clark, L. A. (1984). Negative affectivity: The disposition to experience aversive emotional states. Psychological Bulletin, 96, 465-490. https://doi.org/10.1037/00332909.96.3.465 
RUNNING HEAD: INTIMATE RELATIONS

Weigel, D. J. (2008). A dyadic assessment of how couples indicate their commitment to each other. Personal Relationships, 15(1), 17-39. https://doi.org/10.1111/j.14756811.2007.00182.x

Weiselquist, J., Rusbult, C. E., Foster, C. A., \& Agnew, C. R. (1999). Commitment, prorelationship behavior, and trust in close relationships. Journal of Personality and Social Psychology, 77, 942-966. https://doi.org/10.1037/0022-3514.77.5.942

Winczewski, L. A., Bowen, J. D., \& Collins, N. L. (2016). Is empathic accuracy enough to facilitate responsive behavior in dyadic interaction? Distinguishing ability from motivation. Psychological Science, 27(3), 394-404. https://doi.org/10.1177/0956797615624491

Zech, E., \& Rimé, B. (2005). Is talking about an emotional experience helpful? Effects on emotional recovery and perceived benefits. Clinical Psychology \& Psychotherapy, 12(4), 270-287. https://doi.org/10.1002/cpp.460

Zettle, R. D., Hayes, S. C., Barnes-Holmes, D., \& Biglan, A. (2016). The Wiley handbook of contextual behavioral science. Chichester, UK: Wiley-Blackwell. https://doi.org/10.1002/9781118489857 


\section{RUNNING HEAD: INTIMATE RELATIONS}

Table 1

Definitions of middle-level terms of the model

\begin{tabular}{|c|c|c|c|}
\hline Term & & Definition & Primary consequence \\
\hline Awareness & & $\begin{array}{l}\text { Engaging in mindful awareness of one's self (feelings, needs, values), the } \\
\text { other, and the context of the interaction }\end{array}$ & $\begin{array}{l}\text { Improved vulnerability } \\
\text { and responsiveness }\end{array}$ \\
\hline \multirow[t]{3}{*}{$\begin{array}{l}\text { Turn 1: } \\
\text { Vulnerability }\end{array}$} & $\begin{array}{l}\text { Non-verbal emotional } \\
\text { expression }\end{array}$ & Engaging in regulated, authentic, non-suppressed emotional expression & Safety \\
\hline & Self-disclosure & $\begin{array}{l}\text { Engaging in emotionally congruent, authentic self-disclosures, including } \\
\text { negative emotions/events, positive emotions/events, and closeness } \\
\text { (described as separate term below) }\end{array}$ & Validation \\
\hline & Asking & $\begin{array}{l}\text { Asking for and negotiating specifically what one wants and needs, } \\
\text { including instrumental support for relational and non-relational goal } \\
\text { pursuits, saying "no", and setting limits }\end{array}$ & Giving \\
\hline \multirow[t]{3}{*}{$\begin{array}{l}\text { Turn 2: } \\
\text { Responsiveness }\end{array}$} & Safety & $\begin{array}{l}\text { Providing non-verbal and verbal indicators of synchrony, interest, care } \\
\text { and affiliative intent, including reciprocal vulnerable expressions, in } \\
\text { response to non-verbal vulnerable emotional expressions }\end{array}$ & Expression of closeness \\
\hline & Validation & $\begin{array}{l}\text { Responding to unambiguously convey to a speaker that their self- } \\
\text { disclosures make sense and are valid, verifying underlying emotional } \\
\text { experiences and aspects of self and identity as appropriate }\end{array}$ & Expression of closeness \\
\hline & Giving & $\begin{array}{l}\text { Responding to a speaker's specific wants and needs in ways that are } \\
\text { experienced as genuine and supportive of the speaker's autonomy and } \\
\text { competence as appropriate, including offering apologies and forgiveness } \\
\text { for transgressions }\end{array}$ & Expression of closeness \\
\hline $\begin{array}{l}\text { Turn 3: } \\
\text { Vulnerability }\end{array}$ & $\begin{array}{l}\text { Expression of } \\
\text { closeness }\end{array}$ & $\begin{array}{l}\text { Accepting a partner's responsiveness and vulnerably expressing } \\
\text { closeness, appreciation, and gratitude in response }\end{array}$ & Safety \\
\hline
\end{tabular}




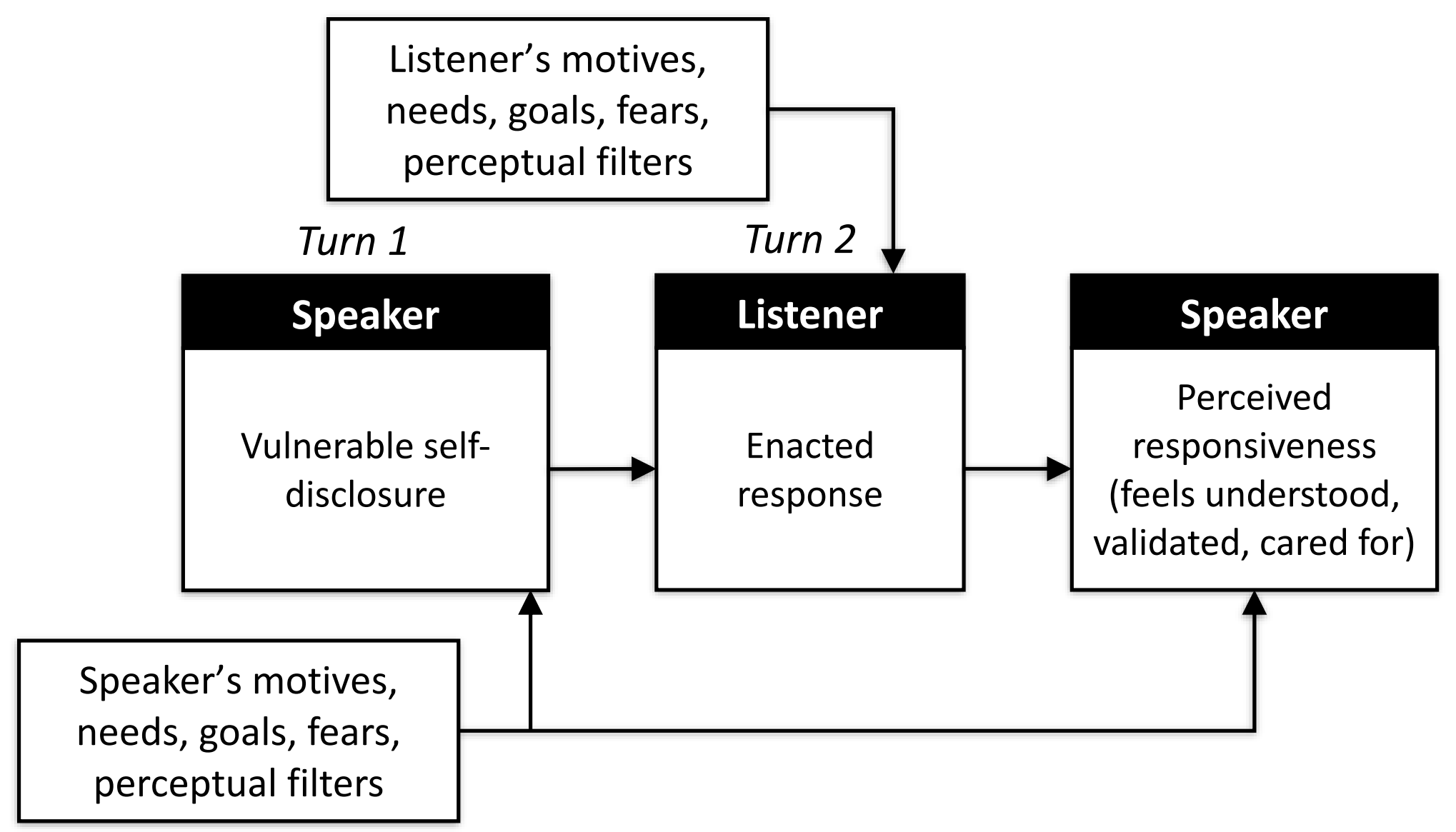

Figure 1. Summary of Original Interpersonal Process Model 


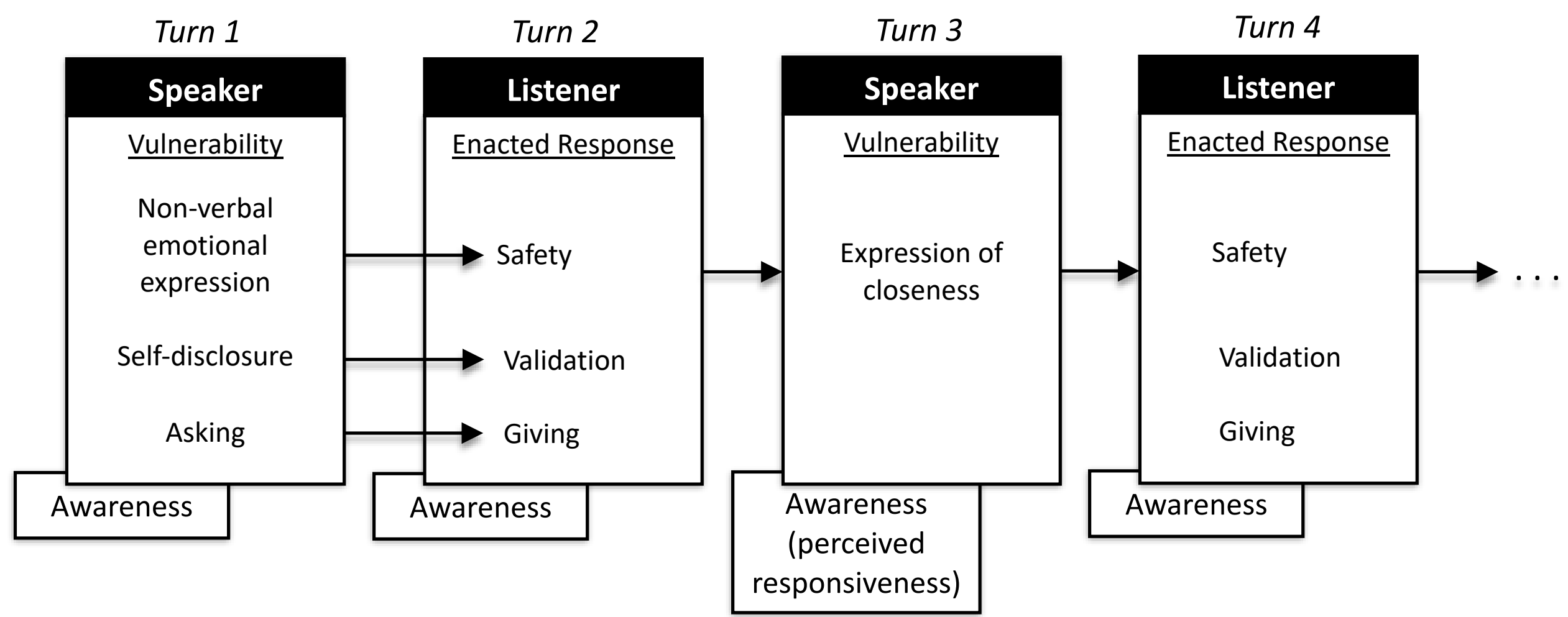

Figure 1. Summary of Contextual-Behavioral Model 